\title{
1 A single cell view of the transcriptome during lateral root initiation in Arabidopsis thaliana
}

Short title: A single cell view of lateral roots

\section{Authors}

9 Hardik P. Gala ${ }^{*}$, Amy Lanctot ${ }^{* 1,2}$, Ken Jean-Baptiste ${ }^{*}{ }^{3}$, Sarah Guiziou ${ }^{1}$, Jonah C. Chu ${ }^{1}$, Joseph E.

10 Zemke $^{1}$, Wesley George ${ }^{1}$, Christine Queitsch ${ }^{3}$, Josh T. Cuperus ${ }^{+3}$, Jennifer L. Nemhauser ${ }^{+1}$

$11{ }^{*}$ These authors contributed equally to the work.

$12{ }^{+}$Corresponding authors

\section{Affiliations}

$15{ }^{1}$ Department of Biology,

$16{ }^{2}$ Molecular and Cellular Biology Program,

$17{ }^{3}$ Department of Genome Sciences,

18 University of Washington, Seattle, WA 98195

20 The author responsible for distribution of materials integral to the findings presented in this article in

21 accordance with the policy described in the Instructions for Authors (www.plantcell.org) is Jennifer

22 Nemhauser (jn7@uw.edu). 


\section{Abstract}

28 Root architecture is a major determinant of fitness, and is under constant modification in response to

29 favorable and unfavorable environmental stimuli. Beyond impacts on the primary root, the environment

30 can alter the position, spacing, density and length of secondary or lateral roots. Lateral root development

31 is among the best-studied examples of plant organogenesis, yet there are still many unanswered questions

32 about its earliest steps. Among the challenges faced in capturing these first molecular events is the fact

33 that this process occurs in a small number of cells with unpredictable timing. Single-cell sequencing

34 methods afford the opportunity to isolate the specific transcriptional changes occurring in cells

35 undergoing this fate transition. Using this approach, we successfully captured the transcriptomes of

36 initiating lateral root primordia, and discovered many previously unreported upregulated genes associated

37 with this process. We developed a method to selectively repress target gene transcription in the xylem

38 pole pericycle cells where lateral roots originate, and demonstrated that expression of several of these

39 targets was required for normal root development. We also discovered novel subpopulations of cells in

40 the pericycle and endodermal cell files that respond to lateral root initiation, highlighting the coordination

41 across cell files required for this fate transition.

42

43 


\section{Introduction}

Plants grow new tissues and organs throughout their lives. To enable this iterative body plan, cells must maintain mechanisms of organogenesis, proliferation, and differentiation. Iterative growth of plants is most easily observed above ground, as plants put out new branches, leaves, and flowers, but equally important is the growth of root systems below the soil. Lateral root development is essential for a plant to remain stably rooted as well as to obtain essential water and nutrients from its surrounding environment. Plants use plasticity in their growth patterns to avoid adverse stimuli and take advantage of favorable ones. In this way, changing root architecture is one of the main mechanisms by which plants can adapt to changing environmental conditions (Khan et al., 2016).

Lateral root development proceeds through three discrete stages, specification, initiation, and emergence. Auxin response exhibits cyclic maxima in the basal meristem with a periodicity of about six hours (De Smet et al., 2007). During specification, cells in the meristematic zone of the primary root are specified as competent to form lateral roots if they transit through the basal meristem when auxin response is high (De Smet et al., 2007). Many other genes oscillate in phase with auxin response in the basal meristem-these genes may be targets of auxin signaling or independent regulators of specification (Moreno-Risueno et al., 2010). These competent cells then exhibit a sustained auxin maximum in the differentiated zone of the root, termed prebranch sites. In Arabidopsis and most dicot plants the pericycle cell layer within these

63 prebranch sites is the cell layer that undergoes lateral root initiation (Beeckman et al., 2001). How this

64 initial transient auxin response is molecularly translated to the sustained auxin response of prebranch sites

65 leading to initiation is unknown.

66 The earliest morphological signal of lateral root initiation is the nuclear migration of two longitudinally

67 adjacent pericycle cells to their shared cell wall. These cells consequently undergo the first anticlinal cell

68 division that initiates lateral root development. GATA TRANSCRIPTION FACTOR 23 (GATA23) is

69 necessary for this nuclear migration to occur (De Rybel et al., 2010). LOB DOMAIN-CONTAINING

70 PROTEIN 16 (LBD16) and LOB DOMAIN-CONTAINING PROTEIN 29 (LBD29) are two other

71 transcription factors shown to play a role in lateral root initiation. These genes are direct targets of AUXIN

72 RESPONSE FACTOR 7 (ARF7) and AUXIN RESPONSE FACTOR 19 (ARF19) that promote cell division

73 (Okushima et al., 2007). Mutants of these genes exhibit a loss of lateral root initiation, and overexpression

74 of LBD16 rescues the arf7arf19 mutant phenotype which also lacks lateral roots (Goh et al., 2012).

75 Further cell divisions of specific plane orientations and structural changes of cell files exterior to the

76 pericycle allows for lateral root emergence. The emergence process is accompanied by strong

77 upregulation of cell wall remodelers that are also targets of auxin signaling (Lewis et al., 2013; 
Ramakrishna et al., 2019) and appears to be the easiest stage of lateral root development to arrest, with many mutants arresting at this stage.

Transcriptomic analyses of lateral root development have been a rich resource for determining key regulators of this developmental process (Vanneste et al., 2005). Careful temporal staging and analyses of different steps during lateral root formation have led to identification of novel regulators (Voß et al., 2015) though the complexity of the pathways regulating this process has also become more apparent.

85 Complicating this analysis is the fact that lateral root development is not cell-autonomous, with many 86 different cell types playing different roles and activating diverse genetic networks during this process.

87 Cell sorting analyses on lateral root development have not been done to parse tissue-specific signals,

88 likely because the regions of the root undergoing this fate transition are prohibitively small for such analyses. Single-cell RNA-sequencing is an alternative approach to obtain transcriptomes on the level of individual cells that requires much less tissue compared to cell sorting. In plants, single-cell RNAsequencing has been used to characterize several plant tissue types, and single-cell analyses of root transcriptomes have identified both previously characterized and novel cell type markers (Jean-Baptiste et al., 2019; Ryu et al., 2019; Shulse et al., 2019; Shahan et al., 2020). To date, single-cell analyses of root tissue have focused on gene expression in the primary root, transcriptome changes between hair cells and non-hair cells, endodermal differentiation, and regeneration of the primary root meristem after injury.

While initiation of lateral roots is known to be regulated by auxin, only a handful of specific molecular markers of this fate switch have been identified. One reason for this scarcity of markers may be that for any given primary root, lateral root initiation only occurs in a very small proportion of xylem pole pericycle (XPP) cells at near basal meristem, which themselves are a very small proportion of the root cells (approximately five percent) (Schmidt et al., 2014). Rarity of lateral root fate transition is further complicated by the pulsatile nature of the auxin signal, making this a highly transient event (MorenoRisueno et al., 2010). To counteract these challenges, we microdissected sections of Arabidopsis roots undergoing gravity-induced lateral root initiation, and subjected the resulting protoplasts to single-cell sequencing. Using this approach, we successfully captured cells from all major cell types of the root outside the meristem. Through pseudotime analyses found that cells identified as lateral root primordia (LRP) are transcriptionally derived from those identified as xylem pole pericycle cells (XPP), consistent with previous morphological analysis (Malamy and Benfey, 1997). Differential gene analyses identified many previously unreported genes that are upregulated in LRP cells as compared to XPP cells. We

110 validated the expression patterns of a subset of these genes using fluorescent reporters. In addition, we

111 developed a CRISPR/dCas9 tool to specifically target the repression of these candidate genes in XPP cells 
112 and found that many of these targets shape root architecture. Finally, we were able to harness the single-

113 cell approach to determine how cells surrounding the developing primordium, specifically endodermal

114 cells overlaying and pericycle cells flanking LRPs, are affected by this fate transition.

115

116 


\section{Results}

118 To examine the developmental transition of lateral root initiation, we used gravistimulation to synchronize the formation of lateral root primordia, and then dissected the region of interest at two time points and performed single-cell transcriptome analyses. Mechanical or gravitropic bending of primary roots in Arabidopsis causes the accumulation of auxin and the formation of a lateral root at the bend (Figure 1A) (De Smet et al., 2007; Ditengou et al., 2008) In our conditions, wild-type plants have formed a primordium at either stage I or II by twenty hours after gravistimulation (Guseman et al., 2015) As our goal was to identify early regulators of lateral root initiation, we analyzed cells twenty hours postbending, when initiation has just begun, and eight hours post-bending, where there are no morphological signs of lateral root development but transcriptome changes have started (Voß et al., 2015). We included a control treatment group where we did not bend the roots but cut a similar region of the primary root. We microdissected the root bend regions to maximize our yield of the rare cell types of interest.

Our experiment yielded 6658 cells with a mean number of 15987 reads per cell and a median of 1383 genes expressed. Of these 6658 cells, 1730 ( $\sim 26 \%)$ cells were from the twenty-hour timepoint, 2443 ( $\sim 37 \%$ ) cells were from the eight-hour timepoint, and $2485(\sim 37 \%)$ cells were from the no bend control

(Supplemental Table 1). Further analysis was performed using Monocle 3 (Trapnell et al., 2014; Qiu et al., 2017; Cao et al., 2019), which uses Principal Component Analysis (PCA) and Uniform Manifold Approximation and Projection (UMAP) to reduce the dimensionality of the dataset and to visualize the relationships among cellular transcriptomes in a two-dimensional space. Our analysis revealed five clusters. Using previously defined cell type markers (Brady et al., 2007; Cartwright et al., 2009), each cluster was assigned a label. Of the 6658 cells, $813(\sim 12 \%)$ cells were classified as cortex \& endodermis, $1015(\sim 15 \%)$ cells were classified as columella/root cap, $1431(\sim 22 \%)$ cells were classified as epidermis, and $3399(\sim 51 \%)$ cells were classified as stele (Figure 1B, Supplemental Figure 1A). These results show that the microdissection was successful in capturing a representative sample of stele cells, as the proportion of these cells in our data was similar to that determined by imaging analyses (Shulse et al., 2019).

\section{Xylem pole pericycle cells are precursors of mature pericycle and lateral root primordia cells.}

147 as belonging to the stele. Of the 3399 stele cells, 216 cells were labeled phloem, 242 cells were labeled

148 xylem, 1206 cells were labeled phloem pole pericycle (PPP), 534 cells were labeled XPP, 336 cells were

149 labeled mature pericycle, 167 cells were LRP, and 698 cells were too ambiguous in their gene expression

150 to assign a label (Supplemental Figure 1B, Supplemental Figure 1C, Supplemental Table 1). A 
bioRxiv preprint doi: https://doi.org/10.1101/2020.10.02.324327; this version posted November 20,2020 . The copyright holder for this preprint (which was not certified by peer review) is the author/funder, who has granted bioRxiv a license to display the preprint in perpetuity. It is made available under aCC-BY-NC-ND 4.0 International license.

A.

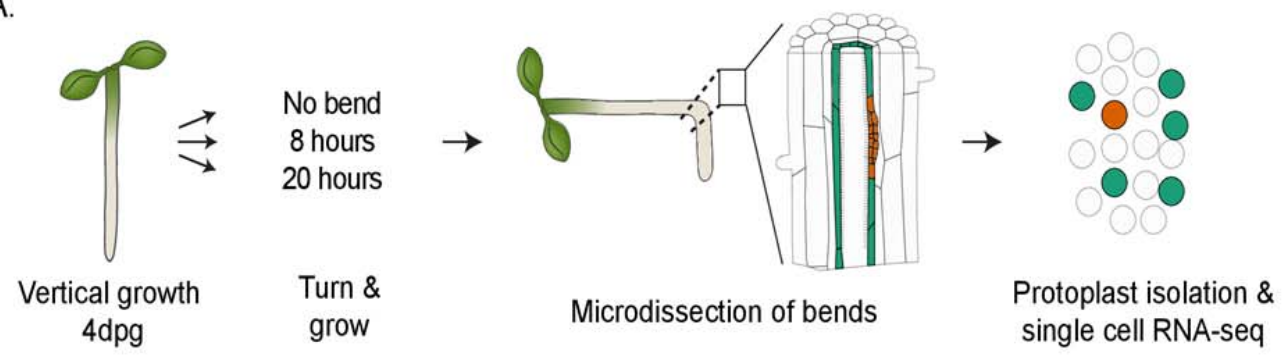

B.
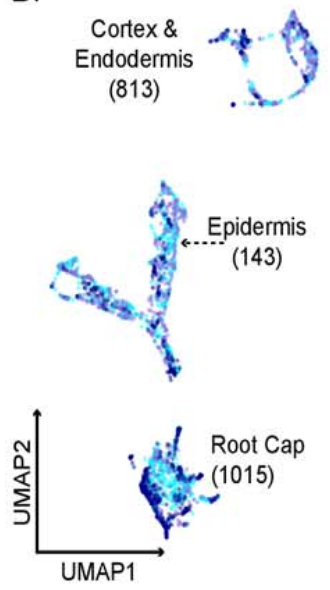

D. PAT2 2
AT1G22530
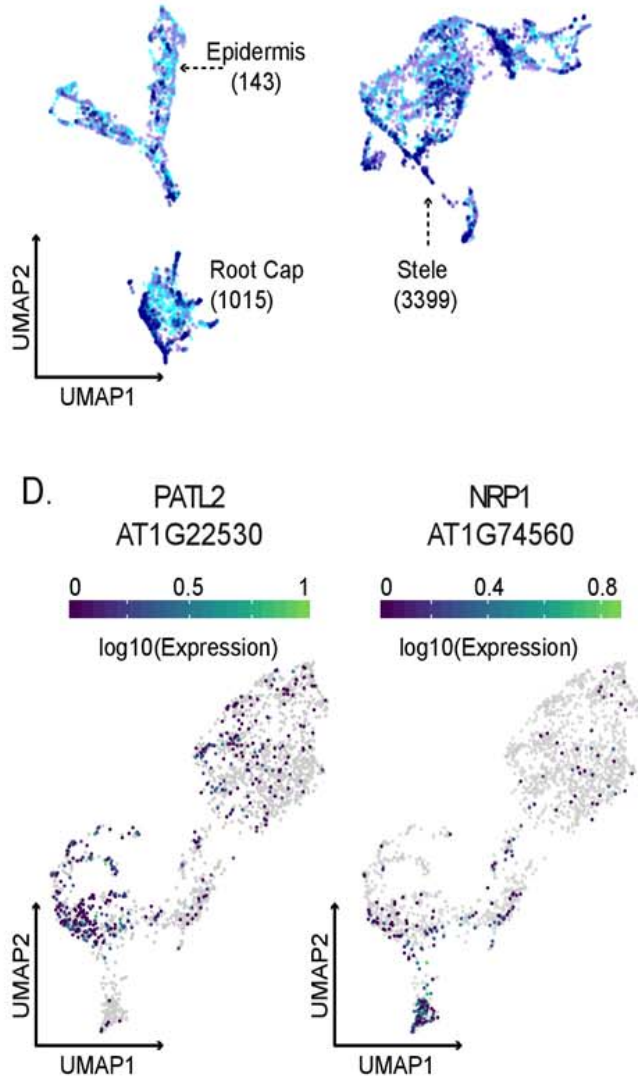

$\log 10$ (Expression)

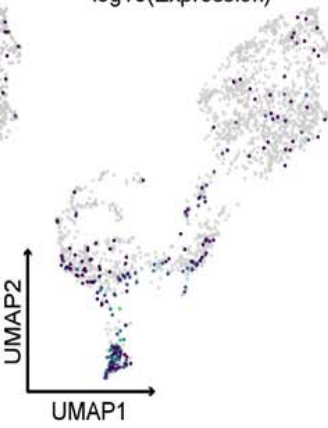

C.

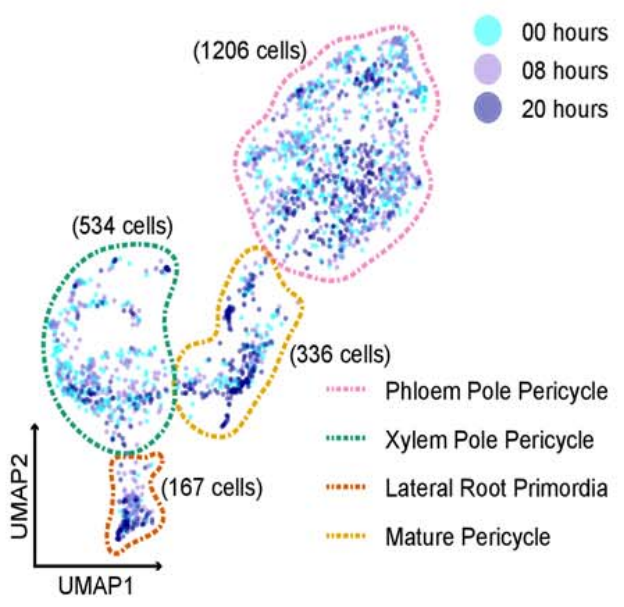

E. Biological Process GO Term Enrichments lateral root morphogenesis water transport (GO:0010102) (GO:0006833)

chromatin organization vesicle-mediated (GO:0006325) transport (GO:0016192) cell cycle cell wall organization (GO:0007049) (GO:0071555)

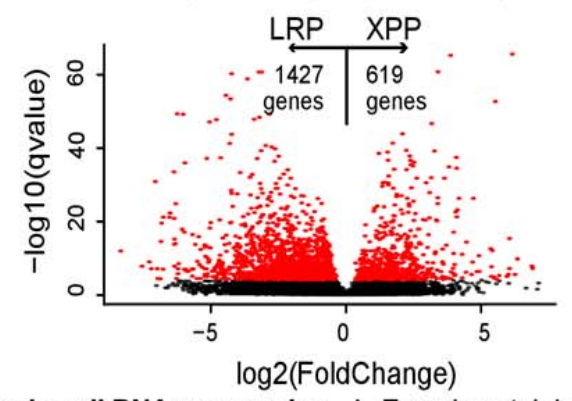

Figure 1: Analysis of lateral root initiation using single-cell RNA-sequencing. A. Experimental design: Arabidopsis thaliana seedlings were grown vertically for 4 days post-germination (dpg) then rotated (or marked, in case of control) and grown for an additional eight or twenty hours. Protoplasts were prepared from microdissected root sections for single-cell RNA sequencing. B. UMAP of all 6658 cells colored by experiment. Cell type identities were assigned to each partition based on a set of marker genes. The cell type identities are indicated on the UMAP with the number of cells corresponding to each cell type. C. UMAP of pericycle specific cells, such as lateral root primordia (LRP), mature pericycle (MP), phloem pole pericycle (PPP), and xylem pole pericycle cells (XPP) colored by experiment. D. Expression pericycle-specific UMAPs of two DEGs between LRP and XPP. E. Scatter plot of the log 2 fold change of average gene expression between XPP and LRP and the Mann Whitney Wilcoxon qvalue. DEGs are colored in red. A selection of GO Terms associated with DEGs are shown above the plot.

151 pericycle-specific UMAP was also generated that included XPP, LRP, PPP and mature pericycle cells 
(Figure 1C). A cell developmental trajectory connected the pericycle sub-clusters and recapitulated the known developmental relationship between these cell types. Trajectories initiating either from the XPP or the PPP converged to mature pericycle but only the XPP (and not the PPP) population branched out toward the LRP, confirming that our results were faithfully recapitulating the known exclusive relationship of XPP to LRP cells (Malamy and Benfey, 1997). The XPP and the PPP cells are expected to differentiate at a similar time, whereas LRP and mature pericycle cells should form later. Our dataset confirmed this developmental progression, as approximately twenty percent of the XPP and PPP cell clusters were from the twenty-hour timepoint whereas approximately fifty percent of the LRP and mature pericycle clusters were from this later timepoint. (Supplemental Figure 1D).

We next attempted to identify genes expressed as XPP cells transitioned to LRP cells. To do this, we carried out a pseudotime analysis originating from the XPP population and connecting to either the LRP or the mature pericycle (Supplemental Figure 2A, Supplemental Figure 2B). Using a false discovery rate (FDR) cutoff of 0.1, 1892 genes were identified as changing in at least one of the trajectories. Of these genes, 878 genes were specific to the XPP to mature pericycle trajectory, 504 genes were specific to the XPP to LRP trajectory, and 510 genes were observed in both trajectories (Supplemental Figure 2C, Supplemental Figure 2D). As XPP cells develop, expression of genes found in both trajectories decreased and most were not expressed at high levels in the LRP cells or the mature pericycle cells. Genes uniquely upregulated across the XPP to the LRP trajectory were overrepresented with transcription factors including the well-known markers of initiation LBD16 and LBD29 (Okushima et al., 2007) as well as WUSCHEL-RELATED HOMEOBOX 5 (WOX5), CYTOKININ RESPONSE FACTOR 2 (CRF2) and $P U C H I$, all of which have previously been shown to play a role or be expressed in lateral root development (Hu and Xu, 2016; Jeon et al., 2016; Goh et al., 2019) (Supplemental Figure 2E). Other genes unique to this trajectory were regulatory kinases like MUSTACHES (MUS), MAP KINASE KINASE 6 (MKK6), and RGF INSENSITIVE 5 (RGI5), which have also been shown to regulate lateral root development (Zeng et al., 2011; Ou et al., 2016; Xun et al., 2020) (Supplemental Figure 2E).

We next performed differentially expressed genes (DEG) analysis on the transcriptomes associated with these different populations. Due to the small number of LRP cells (167 cells i.e. $\sim 2.5 \%$ of all cells), three different statistical approaches were used to perform DEG analysis: a generalized linear model (GLM), the Mann Whitney Wilcoxon (MMW) test, and a recently published packaged called Vision (DeTomaso

183 et al., 2019). We used previously identified LRP-enriched genes as a guide to inform our use of the results 184 from each method. LBD16 and LBD29 were called in all three methods, whereas ARF19 and GATA23 185 were only called in Vision (but narrowly missed with p-values of 0.001 and 0.0004 respectively in MWW 
method). ARF7 was not significantly different in any approach. To compile the most comprehensive list, we generated a list of DEGs that were significantly different between XPP and LRP populations in at least two approaches. We called 1427 DEGs specific to LRP and 619 DEGs specific to XPP cells. Several of these genes have been previously characterized as specific in their expression patterns, and expression maps of these genes reflect this quality (Figure 1D, Supplemental Figure S3, Supplemental Data 1) (Zhu et al., 2006; Tejos et al., 2018).

As expected, a Gene Ontology (GO) term enrichment analysis of the DEGs with higher expression in LRP cells showed a strong enrichment for terms associated with lateral root formation, lateral root morphogenesis, lateral root development, and auxin response. Terms associated with the regulation of translation initiation and RNA processing (Supplemental Data 1) were also enriched, indicating that the transition from the XPP to the LRP requires a burst of de novo protein production. Increased protein production is associated with a stem cell state (Himanen et al., 2004), which correlates with the transition from XPP to early LRP cells which are competent to form all the types of cells of a developing root. Other GO terms associated with the DEGs more highly expressed in LRP were lateral root morphogenesis, cell cycle, and chromatin organization (Figure 1E). a variety of lateral root induction models and experimental designs. We compared our LRP versus XPP DEGs with published datasets to assess differences in single-cell versus whole tissue (or population) methods. We found that roughly half of the genes (including genes regulated by auxin and genes belonging to cell cycle processes) identified by a microarray analysis of induced lateral root development (Vanneste et al., 2005) were included in our set of genes upregulated in LRP cells; only five of these genes were in our set of XPP-upregulated genes (Supplemental Figure S4A). This result suggests our approach faithfully captured genes involved in lateral root initiation and distinguished LRP and XPP cells. A detailed time course analysis of lateral root development using a similar bend assay as what we

213 applied (Voß et al., 2015) allowed us to compare to bulk RNA sequencing data taken at similar timepoints 214 as used in our study. Two thirds of the genes previously found upregulated at nine hours post-bending 215 were contained within our set of genes upregulated in LRP, none of these genes were XPP-upregulated 216 (Supplemental Figure S4B). Roughly half the genes found upregulated at twenty-one hours were within 217 our LRP-upregulated gene list; only nine were in our XPP-upregulated gene list (Supplemental Figure 218 S4B). At both time points, approximately one thousand genes were uniquely found in LRP DEGs from 
our study. The genes that were identified in the previous study but not in ours may be attributed to technical differences or likely are expressed in cell layers outside the pericycle.

We also compared our data to transcriptome assays that did not directly examine lateral root initiation through root bending, but queried related processes in the root. We compared our data to a time course analysis of primary root transcriptomes after auxin treatment (Lewis et al., 2013), as auxin treatment strongly promotes lateral root initiation. We found that thirty-seven LRP-upregulated genes were strongly induced in this dataset in response to auxin, whereas only two XPP-upregulated genes were auxininduced (Supplemental Figure S4C). In contrast, twenty-six XPP-upregulated genes were repressed by auxin treatment, whereas only five LRP-upregulated genes were in this repressed dataset (Supplemental Figure S4C). Another recent analysis identified genes specifically induced by ARF19-mediated auxin response (Powers et al., 2019). We found that 243 of our LRP-upregulated genes overlapped with the set of ARF19-specific auxin-induced genes, while only 19 XPP-upregulated genes did so (Supplemental Figure S4D). We conclude that our data reflect the auxin-inducibility of lateral root initiation, and specifically that this auxin inducibility was at least in part mediated by ARF19. ARF19 is unique among the ARFs in being both auxin-responsive in its own expression pattern (Wilmoth et al., 2005) and a very strong activator of transcription itself (Lanctot et al., 2020) root specification. During specification, cells become competent to form lateral roots if they transit through the basal meristem during an auxin response maximum. Many genes exhibit similar oscillatory behavior to auxin response in the basal meristem (Moreno-Risueno et al., 2010). We found that fifty-eight genes that oscillated in phase with auxin response in the basal meristem were in our set of LRPupregulated genes, whereas only one XPP-upregulated gene oscillated in phase with auxin

243 (Supplemental Figure S4E). However, 213 XPP-upregulated genes oscillated antiphase to auxin in the 244 basal meristem, while only twenty LRP-upregulated genes show antiphase oscillation. How specification 245 and initiation are connected temporally and spatially and how competent cells "remember" their future 246 cell fate is still unknown. Our results suggested that oscillatory behavior of some genes may predict their 247 importance during initiation later in development, and in particular that genes with antiphase oscillation 248 patterns may actively repress lateral root fate. We also compared our dataset to a study that determined 249 genes whose expression was impacted by repressing auxin response specifically in early-stage LRPs

250 (Ramakrishna et al., 2019), and found our LRP-upregulated genes overlapped with nearly two hundred of 251 these genes (Supplemental Figure S4F), again emphasizing the importance of auxin response for 252 establishing lateral root fate. 


\section{Genes upregulated in LRP cells are indicative of cells undergoing fate transitions}

We selected timepoints that should best capture the transition of undifferentiated XPP cells into LRPs. As one of the earliest morphological steps in this process is an asymmetric cell division, followed by many subsequent cell divisions, it is not surprising that a number of LRP-enriched DEGs are involved in cell cycle control. It is already known, for example, that expression of cyclin CYCB1;1 marks lateral root primordia (Beeckman et al., 2001) Interestingly, one of the distinguishing features of XPP cells when compared to PPP cells is that some XPP cells are arrested in G2, whereas all PPP cells are arrested in G1 (Beeckman et al., 2001). This G2 arrest may prime these XPP cells to undergo rapid reintroduction into the cell cycle. We also found enrichment of chromatin remodeling factors in the set of LRP-upregulated genes. Considering lateral root initiation is the first step of organogenesis, it makes sense that broad transcriptional changes, mediated by changes in the chromatin landscape, may be required, but this has not previously been reported (Supplemental Data 1). Finally, we found that genes that promote cell division, differentiation, and "stemness", mostly transcription factors, were also enriched in the set of genes upregulated in LRP cells. Most of these genes have been characterized as regulating development in other meristems, such as the primary root meristem or the shoot apical meristem, but had not been shown to play a role in lateral root development. We chose several candidate genes from these three groups, chromatin regulators (four genes), cell cycle regulators (seven genes) and stemness regulators (six genes) to carry out two types of validation experiments: (1) characterizing their spatial expression patterns with transcriptional reporters in wild-type Col-0 and arf7arf19 mutant seedlings, and (2) phenotypic evaluation of lateral root development in transgenic line with cell-type specific repression of candidate genes.

\section{A novel cell-type specific dCas9-driven repressor system can reveal drivers of lateral root fate}

277 To explore the functional role of candidate genes in lateral root development, we devised a method to

278 repress candidate genes only in the XPP cell lineage. We leveraged the enhancer trap line J0121 which is

279 specifically expressed in XPP cells via a UAS-GAL4 driver system (Laplaze et al., 2005). We first 280 introgressed J0121 into the Col-0 background (referred to hereafter as $\mathrm{J} 0121^{\mathrm{Col}}$ ), and then introduced a

281 UAS-dCas9-TPLN300 repressor (dCas9R) construct with three gene-specific sgRNAs directed to the 282 promoter regions of candidate genes $\left(\mathrm{J} 0121^{\mathrm{Col}}>>\mathrm{dCas} 9 \mathrm{R}\right.$, Supplemental Figure S5, Supplemental Data

283 2). This cell-type specific repression system has several advantages over traditional knockdown and

284 knockout studies. For instance, multiple guides can be used to simultaneously repress several members of

285 the same gene family that may have redundant functions. Additionally, many of the candidate genes we

286 identified as enriched in LRP cells also play roles in embryonic and primary root development, greatly 
bioRxiv preprint doi: https://doi.org/10.1101/2020.10.02.324327; this version posted November 20, 2020. The copyright holder for this preprint (which was not certified by peer review) is the author/funder, who has granted bioRxiv a license to display the preprint in perpetuity. It is made available under aCC-BY-NC-ND 4.0 International license.
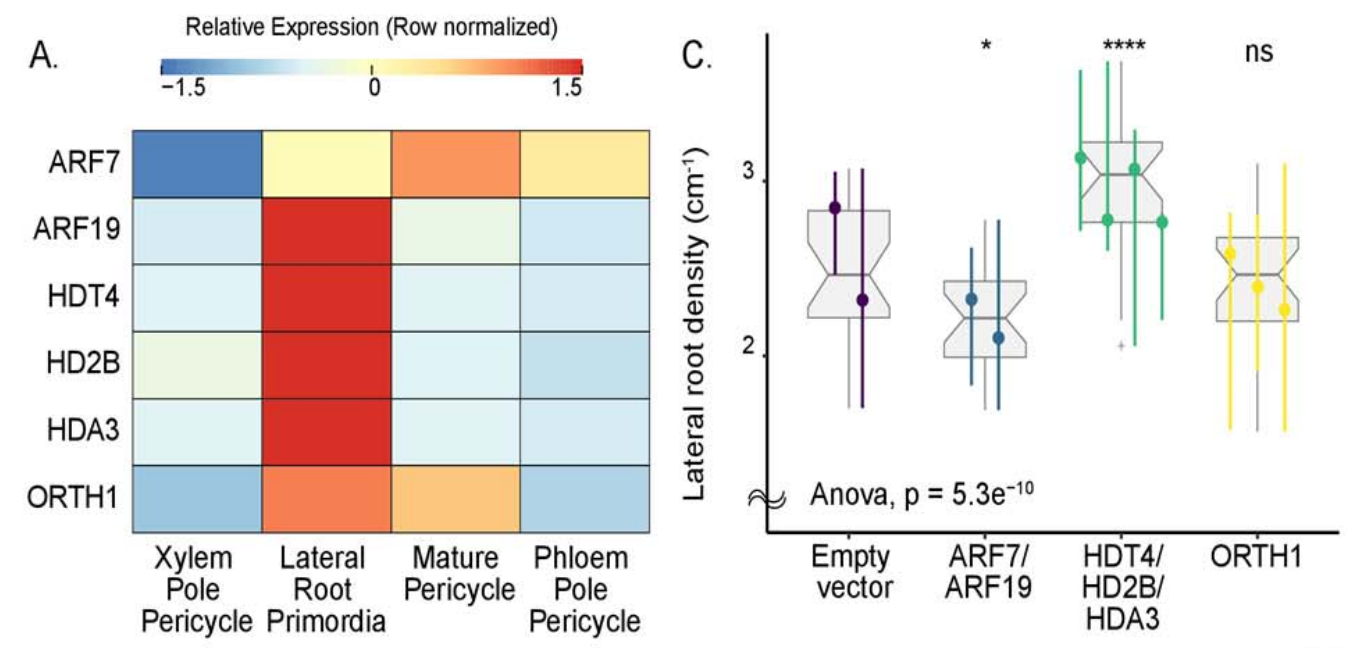

\section{B.}

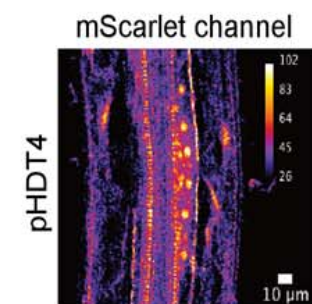

Bright field image

D.
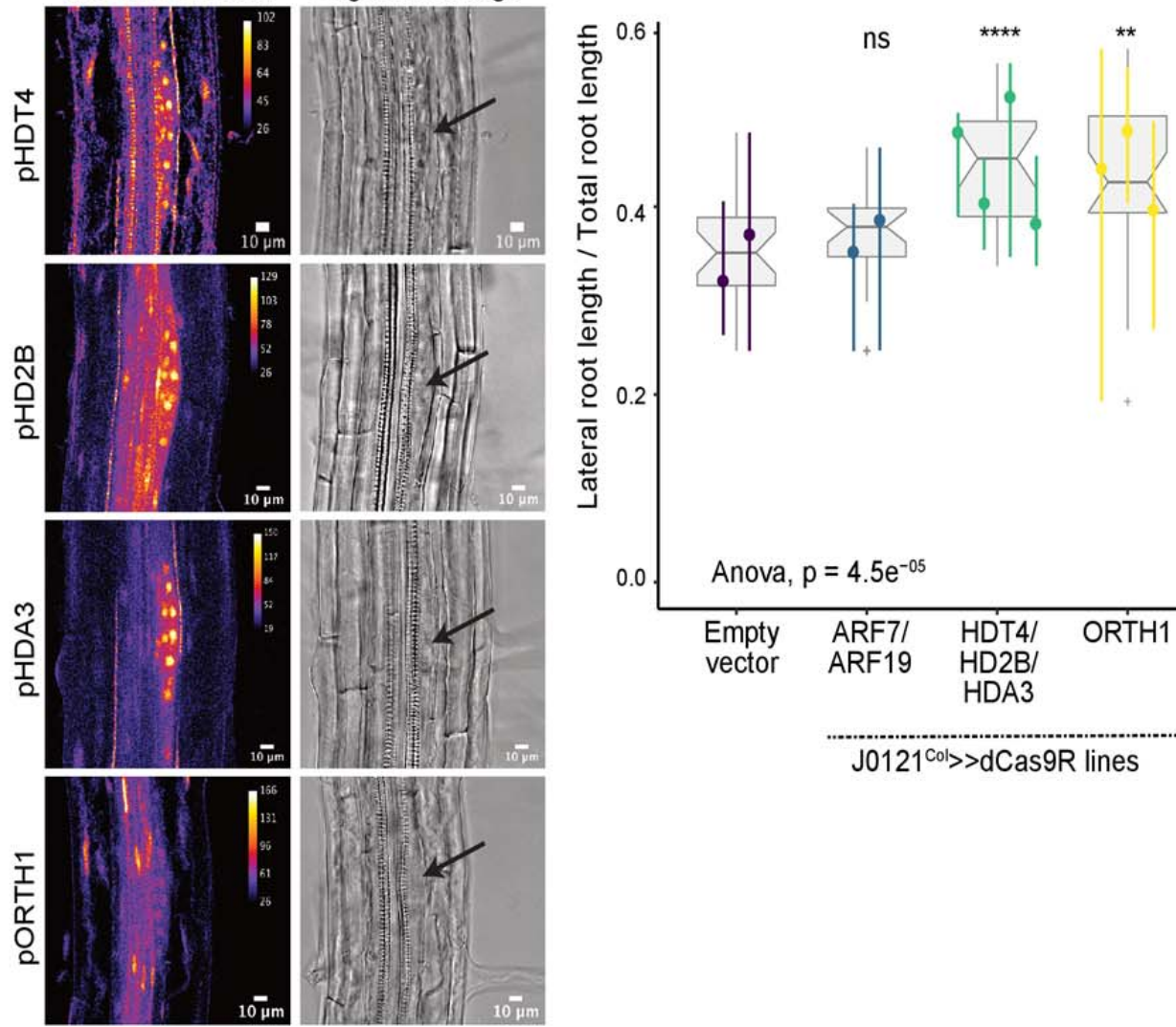

J0121 ${ }^{\text {col }} \gg$ dCas9R lines

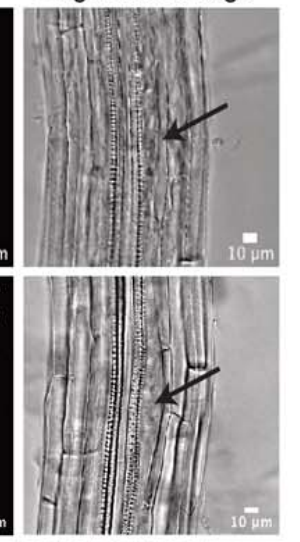

苟

0.0 .

Anova, $p=4.5 \mathrm{e}^{-05}$

$\begin{array}{llll}\text { Empty } & \text { ARF7I } & \text { HDiT4/ } & \text { ORTंH1 } \\ \text { vector } & \text { ARF19 } & \begin{array}{c}\text { HD2B/ } \\ \text { HDA3 }\end{array} & \end{array}$

J0121 ${ }^{\text {col }>>d C a s 9 R}$ lines

Figure 2. Validation experiments on chromatin modifier candidate genes. A. Heatmap (row-scaled) visualizing expression of candidate genes in the pericycle cell clusters from the single-cell library. Scale bar represents the z-score of the normalized expression values. B. Confocal microscopy images of candidate genes' transcriptional reporters in early stage lateral root primordia (left) and bright field image of corresponding primordia (right). C. Lateral root density of J0121 ${ }^{\text {col }} \gg \mathrm{dC}$ Cas $9 R R$ transgenic lines of candidate genes. D. Proportion of total root length contributed by lateral roots of $\mathrm{J} 0121^{\mathrm{col}}>>\mathrm{dCas} 9 \mathrm{R}$ transgenic lines of candidate genes. For $C$ and $D$, significance was determined by pairwise comparison with empty vector control and ANOVA. For each candidate gene, multiple independent transgenic lines have been analyzed; each colored line in the graph represents an individual line. 
of repressing expression of both ARF7 and ARF19. We found that these perturbation lines have significantly reduced lateral root density compared to the empty vector control as expected although they did not fully recapitulate the full suppression of lateral roots seen in arf7arf19 null mutants (Supplemental Figure S6, Figure 2C). This observation is consistent with the small reduction of lateral root number seen in a GATA23-driven CRISPR/Cas9 deletion of ARF7 and ARF19 (Decaestecker et al., 2019). There are at least two likely explanations for the milder phenotype of $\mathrm{J} 0121^{\mathrm{Col}}>>\mathrm{dCas} 9 \mathrm{R}$ compared with the arf7arf19 null mutant. First, repression in $\mathrm{J} 0121^{\mathrm{Col}}$ expression is limited to XPPs and lateral root stages I through III, so there is likely residual ARF protein that persists from expression in pre-XPP fate cells (Dubrovsky et al., 2006). Second, our synthetic repressor may not block all transcriptional activity, leading to hypermorphic rather than amorphic phenotypes. Even given these limitations, the system proved sufficiently sensitive to enable detection of cell type-specific impacts on lateral root development.

\section{Chromatin remodeling factors influence lateral root development}

Three histone deacetylases (HDACs) that are all in the same plant-specific gene family, HISTONE DEACETYLASE 3, HISTONE DEACETYLASE 2, and HISTONE DEACETYLASE 13 (HDA3, HD2B, and HDT4) (Li et al., 2017; Luo et al., 2017), were all enriched in LRP cells in our DEG analysis (Figure 2A), as was the E3 ubiquitin ligase ORTHRUS 1 (ORTH1) which decreases DNA methylation (Kim et al., 2014). Transcriptional reporters of these genes express strongly in early stage primordia (Figure 2B). Expression of HDT4 and HDA3 were specific to LRPs in the differentiated zone of the primary root, though both were also strongly expressed in the meristematic zone of the primary root (Supplemental Figure S7). Their expression in the meristem was strongly decreased in arf7arf19 mutants, suggesting they may be regulated by auxin (Supplemental Figure S7). HD2B was also strongly expressed in LRP cells, as well as in the primary root meristem and other pericycle cells (Supplemental Figure S7).

312 ORTH1 was broadly expressed in the vasculature of the differentiated zone of the primary root, not only

313 in LRP cells (Supplemental Figure S7), which is reflected by its enrichment in mature pericycle cells in

314 our single-cell library (Figure 2A). Its expression was not impacted in arf7arf19 mutant lines

315 (Supplemental Figure S7).

Using J012 ${ }^{\mathrm{Col}}>>\mathrm{dCas} 9 \mathrm{R}$, we targeted all three HDAC genes for repression using distinct guide RNAs for

318 each gene. Simultaneous repression of all three genes caused a strong phenotype, where both the density

319 of lateral roots (Figure 2C) and the proportion of total lateral root length contributed by lateral roots were

320 significantly increased (Figure 2D). The phenotype suggested that the HDACs may repress lateral root

321 initiation and later stages of development. ORTH1 repression in XPP cells did not significantly impact 
lateral root density (Figure 2C), but the proportion of total root length contributed by lateral roots significantly increased (Figure 2D). Thus, ORTH1 may repress lateral root growth only post-initiation. All of these chromatin regulators were expressed strongly in LRP cells, and repressing their function stimulates lateral root growth, suggesting they may act to coordinate cells and promote orderly development.

\section{Cell cycle regulators are active during lateral root development}

We characterized the role of five DEGs enriched in our LRP population that play a role in cell cycle regulation: RECEPTOR FOR ACTIVATED C KINASE 1A, B and 1C (RACK1A, RACK1B and RACK1C), NAP1-RELATED PROTEIN 1 and 2 (NRP1 and NRP2), and CYCLIN-DEPENDENT PROTEIN KINASE INHIBITORS 6 and 11 (SMR6 and SMR11) (Figure 3A). RACK1B and RACK1C interact with protein kinase C (Guo and Chen, 2008). SMR6 and SMR11 are cyclin-dependent kinase inhibitors (Yi et al., 2014), and NRP1 is a histone chaperone required for the G2 to $\mathrm{M}$ transition (Zhu et al., 2006). We generated transcriptional fluorescent reporters of $R A C K 1 B$ and $R A C K 1 C$ and found their expression was indeed specific to early stage lateral root primordia as seen in the single-cell data (Figure 3B). Expression of both $R A C K 1 B$ and $R A C K 1 C$ was lost in the differentiated zone of the primary root in arf7arf19 mutants, which do not form lateral roots, indicating the specificity of their expression to LRP in this zone (Supplementary Figure S8). Expression of these genes in the primary root meristem also was highly decreased in arf7arf19 mutants (Supplementary Figure S8), suggesting ARF7 and ARF19 may be the primary ARFs regulating their expression throughout the root.

We next used $\mathrm{J} 0121^{\mathrm{Col}}>>\mathrm{dCas} 9 \mathrm{R}$ to test for functional relevance of these cell cycle regulators. NRP1 is highly related to NRP2, so we generated a repression line with guides targeting both genes. These lines did not show differences in lateral root density (Figure 3C), but did show a significantly increased proportion of summed total root length that was contributed by lateral roots reflecting longer lateral roots than in the control lines (Figure 3D). RACK1B and RACK1C are highly related and show redundancy with $R A C K 1 A$, so we generated two separate sets of repression lines, one with guides targeting $R A C K 1 B$ and $R A C K 1 C$ and the other with guides targeting all three RACK1 genes. Repression of $R A C K 1 B$ and RACK1C caused a significant decrease in lateral root density (Figure 3C). Interestingly, while repression of all three RACK1 genes did not significantly impact lateral root density, this line did show a significantly increased proportion of total root length contributed by lateral roots (Figure 3D), similar to the NRP1/NRP2 repressed line. Singular repression of SMR6 and concurrent repression of SMR6 and

354 SMR11 did not show differences in lateral root density from the control (Figure 3C), but again showed significantly increased proportion of total root length contributed by lateral roots (Figure 3D). 
bioRxiv preprint doi: https://doi.org/10.1101/2020.10.02.324327; this version posted November 20, 2020. The copyright holder for this preprint (which was not certified by peer review) is the author/funder, who has granted bioRxiv a license to display the preprint in perpetuity. It is made available under aCC-BY-NC-ND 4.0 International license.
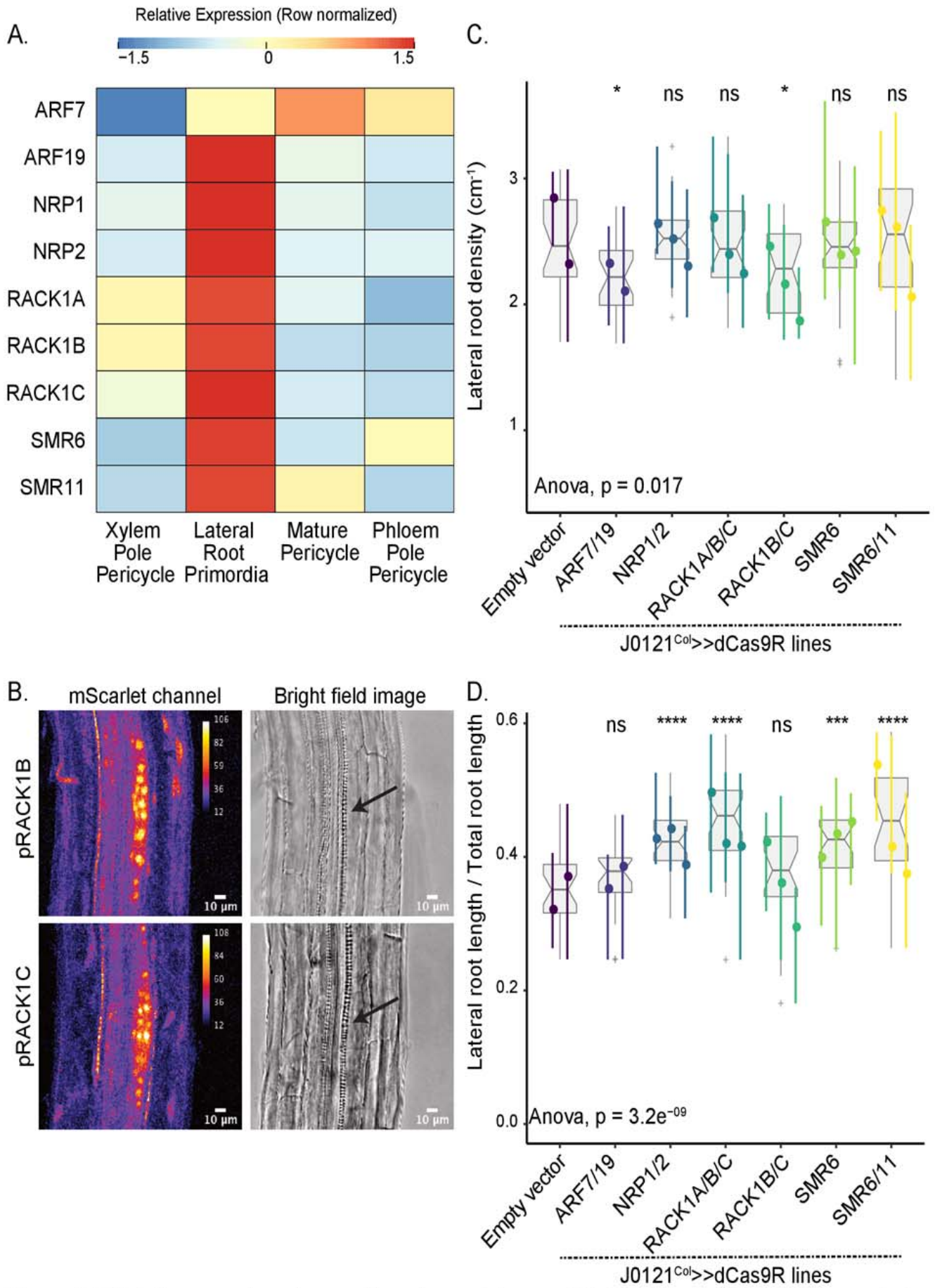

Figure 3. Validation experiments on cell cycle regulator candidate genes. A. Heatmap (row-scaled) visualizing expression of candidate genes in the pericycle cell clusters from the single-cell library. Scale bar represents the z-score of the normalized expression values. B. Confocal microscopy images of candidate genes' transcriptional reporters in early stage lateral root primordia (left) and bright field image of corresponding primordia (right). C. Lateral root density of $\mathrm{J} 0121^{\mathrm{Col}} \gg \mathrm{dCas} 9 \mathrm{R}$ transgenic lines of candidate genes. D. Proportion of total root length contributed by lateral roots of $\mathrm{J} 0121^{\mathrm{Col}} \gg \mathrm{dC}$ as $9 \mathrm{R}$ transgenic lines of candidate genes. For $C$ and $D$, significance was determined by pairwise comparison with empty vector control and ANOVA. For each candidate gene, multiple independent transgenic lines have been analyzed; each colored line in the graph represents an individual line. 


\section{Genes that encode pluripotency and stemness are upregulated in LRP cells}

We chose five DEGs known to play a role in developmental transitions for further validation studies, specifically TARGET OF MONOPTEROS 6 (TMO6), a Dof-type transcription factor originally isolated as a target of ARF5 in embryos (Schlereth et al., 2010), BREVIS RADIX-LIKE 1 (BRXL1), a BRX-like regulator of primary root development (Briggs et al., 2006), LATERAL ROOT PRIMORDIUM 1 (LRP1), which a marker and plays a role in lateral root development (Smith and Fedoroff, 1995; Singh et al., 2020), OVATE FAMILY PROTEIN 8 (OFP8), a transcriptional repressor of KNOX family transcription factors (Wang et al., 2011), and PLETHORA 3 (PLT3), a PLETHORA family gene that interprets auxin gradients in the primary root (Santuari et al., 2016). The presence of genes such as $L R P 1, B R X L 1$, and PLT3, known to regulate early stages of root development, confirmed that our dataset was isolating genes expected to be active early during lateral root initiation. BRXL proteins have recently been shown to play a role in promoting nuclear migration and asymmetric cell division in the development of stomata (Rowe et al., 2019; Muroyama et al., 2020), a process that is also essential during the very first stages of lateral root initiation. OFP8 and TMO6 were somewhat unexpected discoveries, given that ovate family proteins have primarily been characterized in fruit development (Wang et al., 2016) and TMO genes have primarily been characterized in embryonic development (Schlereth et al., 2010).

Expression of all of these genes showed enrichment in LRP cells, though TMO6 expression was most enriched in PPP cells (Figure 4A), consistent with its known role in phloem cell division and differentiation (Miyashima et al., 2019). Reporters of PLT3 (Galinha et al., 2007), LRP1 (Smith and Fedoroff, 1995) and TMO6 (Schlereth et al., 2010) have previously been published, so we only generated transcriptional reporters of OFP8 and BRXL1. Both showed strong and specific expression in lateral root primordia (Figure 4B). Expression of the TMO6 reporter had not been previously analyzed in XPP or LRPs. We found that indeed it was strongly expressed in developing primordia, as predicted from the single-cell analysis. Nearly all of this expression was lost in arf7arf19 mutants (Supplemental Figure 9), suggesting that, at least in the root, TMO6 is primarily a target of these ARFs rather than ARF5. TMO6, BRXL1 and OFP8 were not expressed in the primary root meristem, (Supplemental Figure 9) making them potentially useful for targeting engineering efforts specifically to lateral roots. different ways. Repression of PLT3 caused a significant increase in both lateral root density (Figure 4C) and the proportion of total root length contributed by lateral roots (Figure 4D), suggesting PLT3 may

389 repress both lateral root initiation and emergence post-initiation. Repression of TMO6 did not impact 390 lateral root density (Figure 4C), but did cause a significant increase in the proportion of total root length 
bioRxiv preprint doi: https://doi.org/10.1101/2020.10.02.324327; this version posted November 20, 2020. The copyright holder for this preprint (which was not certified by peer review) is the author/funder, who has granted bioRxiv a license to display the preprint in perpetuity. It is made available under aCC-BY-NC-ND 4.0 International license.
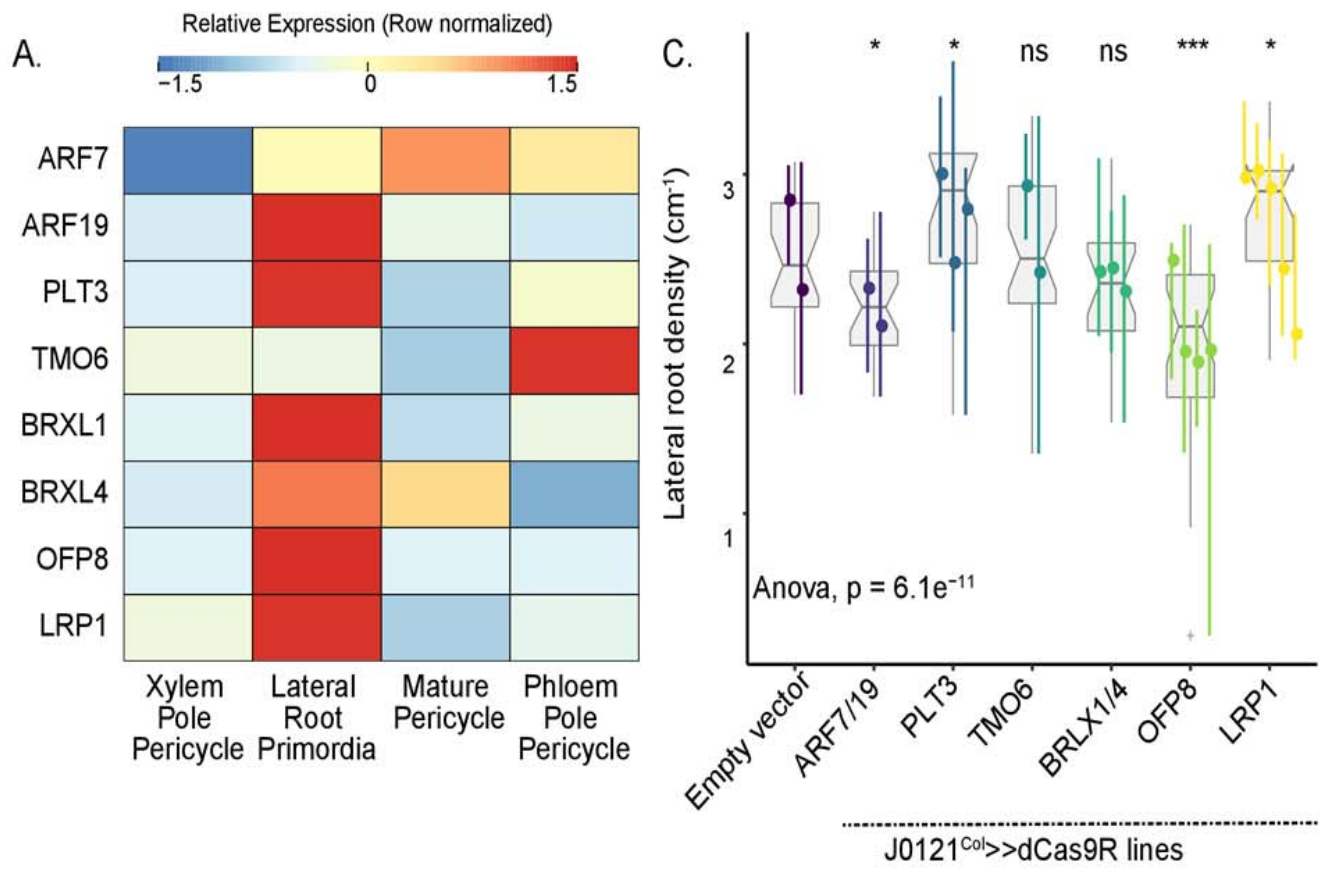

B.

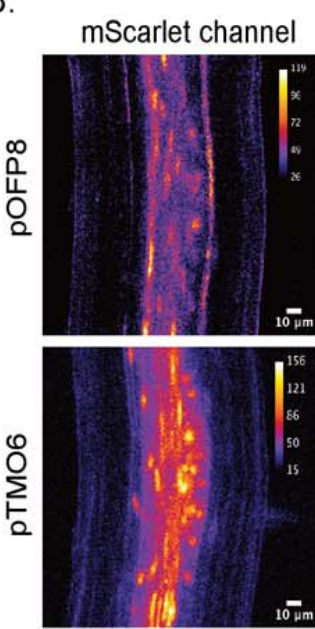

Bright field image

D.
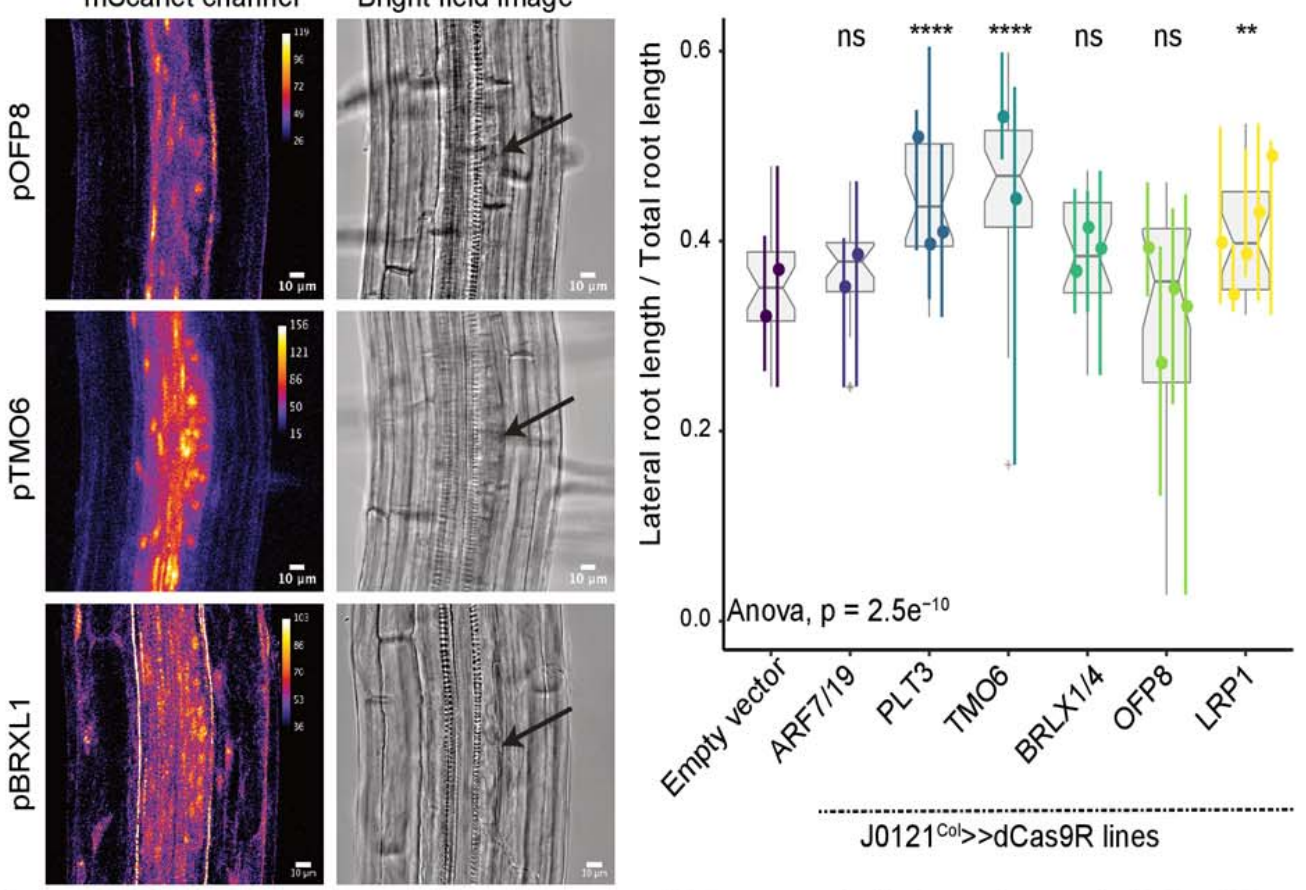

Figure 4. Validation experiments on stemness candidate genes. A. Heatmap (row-scaled) visualizing expression of candidate genes in the pericycle cell clusters from the single-cell library. Scale bar represents the z-score of the normalized expression values. B. Confocal microscopy images of candidate genes' transcriptional reporters in early stage lateral root primordia (left) and bright field image of corresponding primordia (right). C. Lateral root density of $\mathrm{J} 0121^{\mathrm{Col}}>>\mathrm{dC}$ Cas $9 \mathrm{R}$ transgenic lines of candidate genes. D. Proportion of total root length contributed by lateral roots of $\mathrm{J} 0121^{\mathrm{Col}} \gg \mathrm{dC}$ as $9 \mathrm{R}$ transgenic lines of candidate genes. For $C$ and $D$, significance was determined by pairwise comparison with empty vector control and ANOVA. For each candidate gene, multiple independent transgenic lines have been analyzed; each colored line in the graph represents an individual line.

contributed by lateral roots (Figure 4D), suggesting it may act on lateral root development post-initiation. 
Repression of LRP1 in XPP cells significantly increased both lateral root density (Figure 4C) and the proportion of total root length that are lateral roots (Figure 4D), a phenotype that matches previously reported overexpression lines of $L R P 1$, which showed decreased lateral root density (Singh et al., 2020). Concurrent repression of $B R X L 1$ and its close homolog BRXL4 did not significantly impact either lateral root density (Figure 4C) or the proportion of total root length that are lateral roots (Figure 4D), despite its strong expression in LRP cells. We did observe irregular spacing of lateral roots and shorter primary roots in $B R X L / B R X L 4$ repression lines, suggesting they may play a role in lateral root emergence (Supplemental Figure 9). Repression of OFP8 exhibited unique behavior in our perturbation lines, as these lines showed significantly decreased lateral root density (Figure 4C). OFP8 has not previously been characterized to play any role in root development, and this strong effect on lateral root initiation and its strongly specific expression in LRP is notable. OFP8 repression did not impact the proportion of total root length contributed by lateral roots (Figure 4D) but these lines had shorter primary roots

\section{(Supplemental Figure 6).}

\section{Non-LRP cells populations undergo transcriptional changes and fate transitions in response to}

\section{lateral root initiation}

408 Formation of a new lateral root is a self-organizing process during which a very limited number of competent XPP cells undergo repeated cell divisions to initiate lateral root organogenesis (Torres-

410 Martínez et al., 2020). Continued development of the new root requires biophysical restructuring of the

411 surrounding cell files. Signatures of lateral root development are seen outside the pericycle at pre-

412 emergence stages of development, including during early initiation (Vermeer et al., 2014). Feedback on

413 auxin signaling and changes in auxin transport patterns in the endodermis (Marhavý et al., 2013) and the

414 vasculature (De Smet et al., 2007; Porco et al., 2016) are also essential for the first steps of lateral root

415 initiation. Because our single-cell RNA sequencing dataset allowed us to examine the transcriptional state

416 of these different cell layers independently, we examined which of the non-pericycle cell files contribute

417 to transcriptional changes in response to this fate switch. For this we leveraged DEGs (945 genes)

418 identified from a previous bulk RNA transcriptome study of bend-induced lateral root initiation (Voß et

419 al., 2015) corresponding to the twenty hour post-bend timepoint in our study, and mapped the expression

420 of these genes to our cell type resolved dataset (Figure 5A). As expected, most of these genes showed

421 high expression in the LRP population and very low expression in the XPP population. In addition, we

422 found strong enrichment of certain groups of genes in non-LRP populations, especially in those

423 categorized as mature pericycle, endodermis cells and root cap cells. 


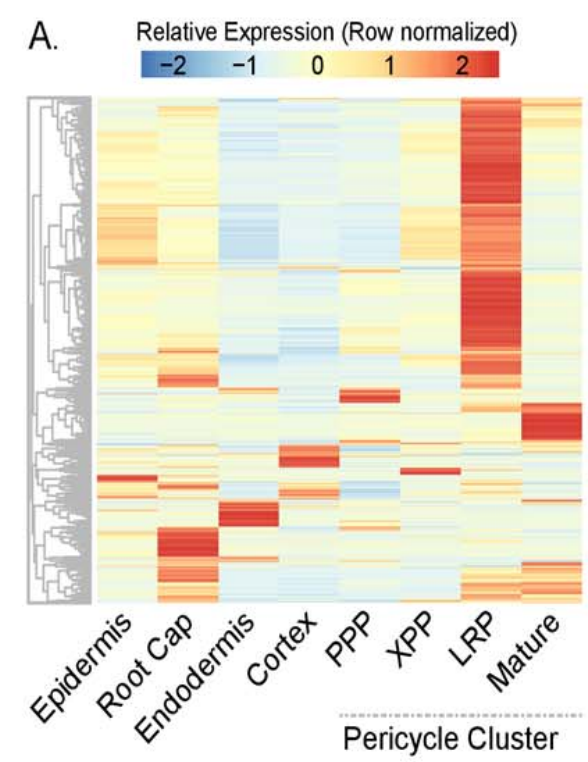

C.

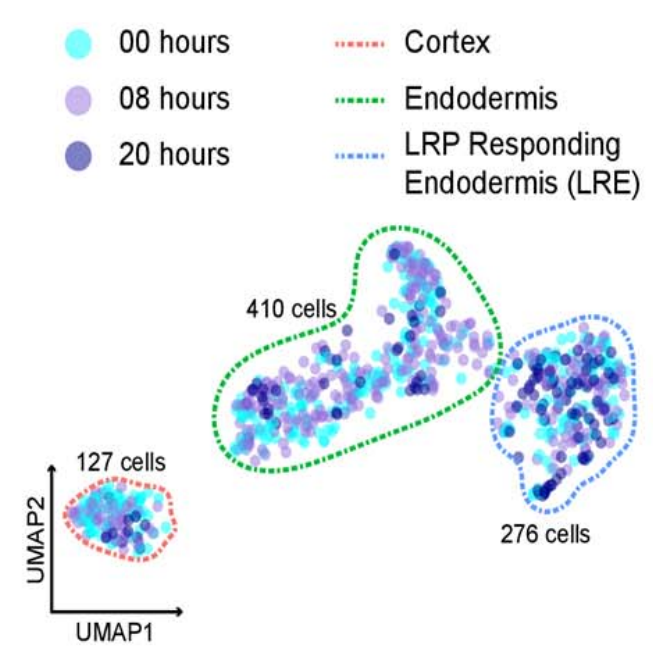

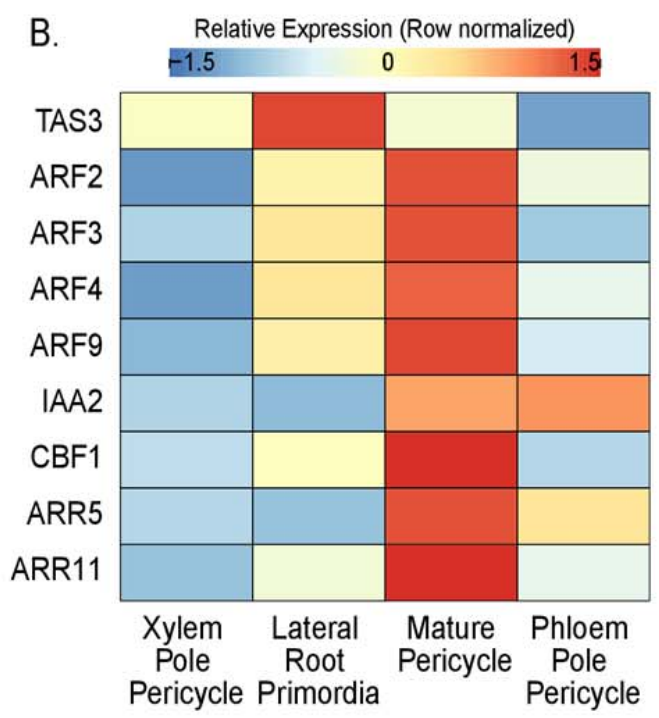

D. ORE1 (AT5G39610)

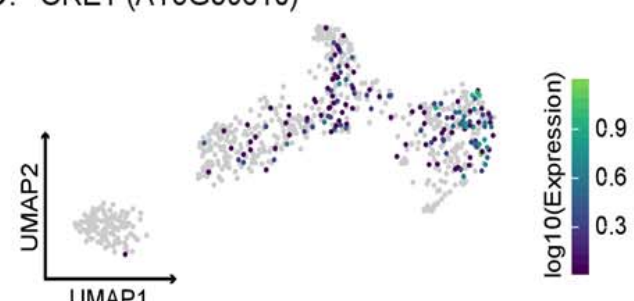

E. ATG8A (AT4G21980)

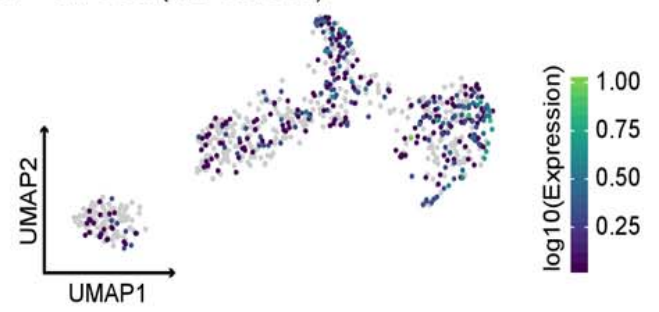

F.

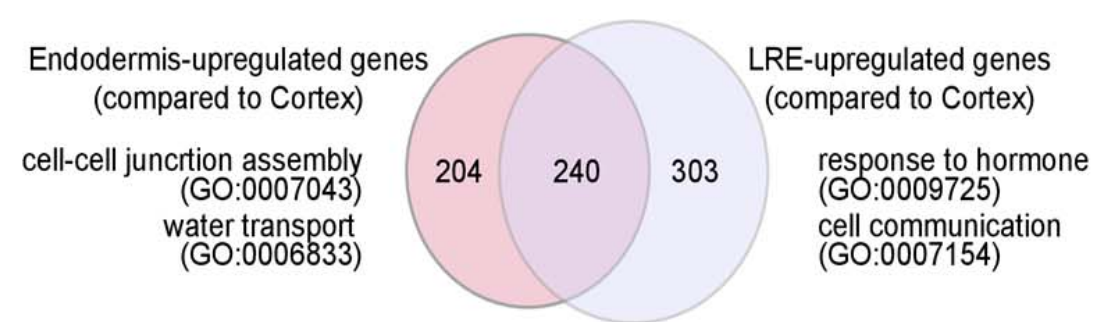

Figure 5. Analysis of non-LRP cells in the single-cell library. A. Heatmap (row-scaled) of expression patterns of previously-identified LR-specifying genes in different cell clusters. B. Expression heatmap (row-scaled) of specific auxin-inducing and auxin-repressing genes in different stele cell clusters. C. UMAP of Cortex, Endodermis, and Lateral Root Responding Endodermis (LRE) cells. D. Expression UMAP of ORE1, a NAC transcription factor that promotes autophagy of endodermal cells overlying LRPs. E. Expression UMAP of AT8GA. F. Gene ontology of genes enriched in endodermis and LRE cell populations. The Venn diagram represents DEGs upregulated in endodermis in comparison to the cortex and upregulated in LRE in comparison to the cortex. A selection of GO terms for each of these sets of DEGs are shown.

425 We focused first on genes showing strong expression in the mature pericycle, as these cells could be 
directly in contact with the initiating primordium. To assess if the genetic circuits regulating the XPP to mature pericycle transition were linked to lateral root development at the bend, we examined the genes expressed in our pseudotime analysis of the transition of XPP cells to mature pericycle cells as compared to the genes expressed in the trajectory the transition of XPP cells to LRP cells (Supplemental Figure 2A-D). Genetic signatures in this mature pericycle trajectory suggested that these cells, acting as the outgroup for this fate transition, nonetheless were responding to lateral root development, though in a very distinct way from cells within the XPP to LRP trajectory. One gene that was expressed in XPP cells and LRP cells close to the branch point is TRANS-ACTING siRNA3 (TAS3). TAS3 promotes lateral root development by inhibiting the class $\mathrm{B}$ auxin response factors ARF2, ARF3 and ARF4 (Marin et al., 2010) Consistent with this pattern, $A R F 2$ transcripts were found only in the mature pericycle trajectory. While TAS3 expression is fairly consistent across XPP, LRP, and mature pericycle cells, ARF2, ARF3, and $A R F 4$ show greater expression in the mature pericycle cell population as compared to the XPP population, and also show high expression in PPP cells (Figure 5B). As LRPs never initiate from PPP, strong expression of these repressor ARFs in mature pericycle cells and PPP cells may indicate that these genes are repressing auxin response, and thus lateral root development, in these cells. surrounding pericycle cells, allowing for the proper spacing of lateral roots along the axis of the primary root (Murphy et al., 2016; Toyokura et al., 2019; Trinh et al., 2019). The strong expression of genes that repress auxin response in mature pericycle cells suggests one mechanism for this inhibition. Further evidence in support of this model is the expression of another repressor ARF, ARF9, and the auxin repressor IAA2 only in the mature pericycle trajectory. Uniquely expressed in this trajectory are also two cytokinin response factors, ARABIDOPSIS THALIANA RESPONSE REGULATORS 5 and 11 (ARR5 and ARR11), which are known to inhibit auxin response, repress lateral root development and coordinate uniform spacing of lateral roots (Mason et al., 2005; To et al., 2004). A target of cytokinin signaling, CFB1, which is specifically expressed in the flanking zone of developing LRPs (Brenner et al., 2017) is also unique to this trajectory. Together, these data suggest that cells that were initially categorized as mature pericycle may be more accurately described as LRP-flanking pericycle cells, and this flanking fate

454 is specifically induced by the initiation of a new root.

\section{Lateral root development shows strong signatures in endodermal transcriptomes}

457 We next examined the impact of lateral root initiation on the endodermal cell file which is immediately

458 exterior to the pericycle. We first re-clustered the 813 cell partition labeled as cortex and endodermis

459 cells. This analysis revealed three distinct cell populations. The first population was a set of 127 cells 
which expressed cortex marker genes, the second population was a set of 410 cells which expressed endodermis marker genes, and the third population of 276 cells branching out from endodermis population (Figure 5C, Supplemental Figure 10A, Supplemental Figure 10B). This third population was transcriptionally most similar to the 410 cells expressing endodermis marker genes, and twenty-six percent of the cells in this third population were from the twenty hour timepoint. As a comparison, about eight percent of the 127 cell population were from the twenty hour timepoint, while about nine percent of the 410 cell population were from the twenty hour timepoint. This third population also had the highest expression of the NAC transcription factor, ORESARA1 (ORE1) and autophagy marker gene ATG8a (Figure 5D and E). ORE1 is a positive regulator of programmed cell death and autophagy marker gene ATG8a are specifically expressed in cells overlying LRPs (Escamez et al., 2020). ORE1 expressing cells eventually die in order to make space for the lateral root to emerge (Escamez et al., 2020). As such, we categorized these three populations as cortex (127 cells), endodermis (410 cells), and lateral rootresponding endodermis (LRE) (276 cells) (Supplemental Table 1, Supplemental Figure 10A). compared to cortex cells as an outgroup. As in the XPP-LRP comparison, only genes that were called significantly different in at least two methods were called as DEGs (Supplemental Figure 11). This analysis yielded over 2000 DEGs between endodermis and cortex, and over 3000 DEGs between LRE and cortex. As expected, there was large overlap between these two sets of DEGs (Supplemental Data 3). A smaller set of genes were identified that were specific to the endodermis cells (204 genes), and specific to the LRE cells (303 genes), while 240 were commonly upregulated genes in endodermis and LRE (Figure 5F). The DEGs specific to the endodermis cells were enriched for GO terms associated with cell-cell junction assembly and water transport, while the DEGs specific to the LRE cells were enriched for GO terms associated with hormone response, auxin homeostasis, cell communication, lateral root development, and multiple stress responses (Supplemental Data 3).

Pseudotime analysis was performed to identify genes driving the transition from endodermis to the lateral root endodermis. This analysis showed a branch point between the two cell types. One branch that we termed the "main branch" was composed mostly of cells from the eight hour time point, and was transcriptionally similar to the rest of the endodermis cluster. The other branch that we called the "LRE branch" led towards the LRE cluster (Supplemental Figure 12A). Again, two separate trajectories were analyzed, one containing only endodermis cells and another containing endodermis cells below the branch

492 point and LRE cells. This yielded a set of 2082 genes whose expression changed over the course of the 493 cell developmental trajectory. After removing genes upregulated in cortex cells, a small set of genes were 
494 identified as specific to the main branch (154 genes) and to the LRE branch (648 genes) (Supplemental

495 Figure 12B, Supplemental Data 3). GO analysis for the main branch specific genes showed enrichment

496 for terms associated with responses to various stimuli. An example of a main branch specific gene is

497 DEEPER ROOT 1 (DRO1) (Supplemental Figure 12C). Negatively regulated by auxin, DRO1 is

498 involved in gravity sensing in the root tip and determining lateral root branch angle (Uga et al., 2013;

499 Guseman et al., 2017; Waite et al., 2020). DRO1 loss of function mutants have increased horizontal

500 lateral roots and have trouble establishing auxin gradients in response to gravistimulus. In our dataset, the

501 majority of cells expressing DRO1 are endodermal cells, suggesting these cells play a specific role in

502 response to gravity. The LRE branch genes were enriched for GO terms associated with lateral root

503 development, auxin homeostasis, auxin transport, and biosynthetic processes. Examples of LRE branch

504 specific genes are WRKY75 and PINS-LIKE 5 (PILS5) (Supplemental Figure 12D). WRKY75 is induced

505 particularly in phosphate starvation (Devaiah et al., 2007), and PILS5 is an auxin efflux carrier regulating

506 intracellular auxin homeostasis, both independently having a role in controlling root architecture. These

507 along with gene ontologies pertaining to several biotic and abiotic stress responses (Supplemental Data

508 3) indicates that LRE cell population seems to be primed to dynamically assess environment and thereby

509 regulate lateral root emergence. 


\section{Discussion}

513 Among the greatest mysteries in development is the process by which a stem cell begins proliferating and

514 partitioning its progeny into increasingly determined cell fates. In plants, the initiation of lateral root

515 development is among the best understood of these processes, yet many fundamental questions remain.

516 Auxin is clearly a critical signal, but what other pathways interact with auxin response or regulate

517 developmental steps downstream of auxin perception are still largely unknown. One key piece of missing

518 information is a full accounting of transcriptional changes in the lateral root primordia during the critical

519 window of initiation. In this study, we performed single-cell RNA sequencing at two timepoints on

520 regions of roots where lateral root initiation was taking place. We identified cells of all cell types of the

521 root outside the meristem in our population, including cells expressing lateral root markers. Through

522 differential gene expression analysis, we identified genes upregulated in LRP cells as compared to XPP

523 cells, many of which were indicative of cells undergoing cellular differentiation and organogenesis. We

524 also identified a subset of pericycle and endodermal cells outside of the primordium itself that appear to

525 be responding to the initiation of a new root.

We chose several genes for further study. Transcriptional reporters confirmed that most were expressed in early stage lateral roots, and that this expression was in many cases dependent on ARF7 and ARF19. Several reporters showed additional expression in other parts of the root, including the primary root meristem. OFP8 and BRXL1 were expressed specifically in LRPs, making them potentially useful tools for studying and engineering root architecture. Repression of many of our candidate genes in XPP cells caused defects in lateral root development, a previously unknown role for some of them. For example, $H D 2 C$ and $H D 2 B$ have been linked to down-regulation of ribosomal biogenesis genes (Chen et al., 2018), a process we found to be strongly induced in lateral root primordia. This connection is consistent with our finding that repression of these genes led to higher density of lateral roots. It also highlights the fact that genes that are upregulated during primordia initiation may be important either for promoting

537 developmental progression or for providing checks to keep cellular events coordinated or appropriately

538 controlled. OFP8 has been reported to act as a direct transcriptional repressor (Wang et al., 2011), and as 539 a regulator of cell division patterns and organ shape via modification of the cytoskeleton (Snouffer et al., 540 2020).

542 Within the primordium itself, careful regulation of cell division and growth are essential for the formation 543 of a primordium with normal morphology. The majority of our $\mathrm{J} 0121^{\mathrm{Col}}>>\mathrm{dCas} 9 \mathrm{R}$ transgenic plants

544 exhibited increased lateral root density or increased lateral root length as a proportion of total root length.

545 These results suggest that these target genes may normally act as repressors of lateral root initiation or 
emergence. When they are repressed, development is accelerated. One interpretation is that cell division and lateral root development are the default state of competent pericycle cells. This would be analogous to the situation in the root epidermis where becoming a root hair is the default state that must be actively repressed in non-hair cells (Berger et al., 1998). This hypothesis is supported by experiments where laser ablation of surrounding tissue causes unrestricted cell division in the pericycle cell file (Marhavý et al., 2016), and where exogenous auxin treatments trigger lateral root initiation in every pericycle cell

552 (Himanen et al., 2002).

Using cell-type specific repression of our candidates in XPP cells allowed us to avoid several problems with global mutant analyses. For example, PLT3 and BRXL1 play critical roles in the primary root meristem, making interpretation of any lateral root phenotypes difficult. A narrower scope of repression may also reduce the likelihood of compensation from paralogs. The repression lines decrease expression only in XPP cells and in LRP cells up to stage IV. This tissue-specific expression may explain the phenotypic difference between our PLT3-repressed line and plt3 plt5 plt7 mutants, which show decreased lateral root emergence (Du and Scheres, 2017). It is possible that PLT3 is playing opposing roles in different cell files of the root or at different points in lateral root development, depending on the interacting partners that are present in these cell files at these developmental stages. Alternatively, the phenotypes we observed could reflect feedback effects on other genes in the same gene regulatory network. The analysis performed here is likely to have missed phenotypes, especially those that rely on complex interactions with a soil environment or on a different set of metrics (Fitter, 1987; Lynch, 1995). For example, the irregular spacing and rate of growth of lateral roots in our BRXL1/BRXL4-repressed lines did not significantly impact the metrics we tested (Supplemental Figure 9). Introgression of J0121 into different accessions would allow access to a broader array of cryptotypes (Chitwood and Topp, 2015; Ristova et al., 2018), and a more holistic view of impacts on root architecture.

We found that our single-cell experiments captured the majority of previously reported LRP-enriched

572 transcripts in our LRP-assigned cells, and these transcripts were not enriched in our XPP-assigned cells.

573 We additionally found many more LRP-enriched genes in our library than in bulk transcriptomes,

574 underlining the utility of this method in examining rare developmental events. Many of our XPP-

575 upregulated genes oscillate antiphase to auxin response in the basal meristem. These antiphase-oscillatory

576 genes are upregulated in cells that are not competent to form lateral roots. They may be actively

577 preventing lateral root initiation in XPP cells, in alignment with the hypothesis that LRP-competency may

578 be the default state of XPP cells. Notably, there are also 698 cells within our stele cluster that were too

579 ambiguous in their gene expression to assign a cell label. It is possible some of these cells are precursors 
to stele cells, such as XPP precursors that are not yet lateral root competent. How distinct lateral root competent and non-competent XPP cells are is unknown — the only known distinguishing feature between the two is a characteristic auxin response maximum or lack thereof. Additional differential gene expression between different timepoints within the XPP cluster and this non-assigned stele cell cluster may yield novel insights.

Though lateral root development is specific to xylem pole pericycle cells, the process is not cellautonomous. Our analysis identified a population of endodermal cells distinct from the main endodermis branch. These cells were enriched in the expression of genes falling in ontology categories for hormone and auxin response, cell-cell communication, and lateral root development, making a strong case that they are responding to developing primordia in underlying pericycle cells. They were also enriched in ORE1 expression, a gene that has recently been shown to play a role in lateral root initiation and emergence through programmed cell death of tissue overlying LRPs (Escamez et al., 2020). Consequently, this population of endodermal cells appears to be responding to lateral root initiation in neighboring pericycle cells, and forging a path for the incipient primordium. primordium and responding with a distinct transcriptional program that included a combination of auxinrepressing and cytokinin-induced genes. A dynamic analysis of the gene regulatory network governing lateral root development established that early cell fate determining genes initiate multiple genetic feedback loops that divide the developing primordium into two zones, a central proliferative core and flanking cells that have inhibited expression of meristematic genes to repress cell division (Lavenus et al., 2015). Notably, PPP cells in our dataset also show strong expression of several auxin-inhibitory genes. PPP cells never initiate lateral root development, even though these cells receive the same auxin maximum signal as XPP cells during specification. It is possible these repressors of auxin signaling act to 605 prevent spurious root development in multiple cell files. As human activity changes the climate and environments in which plants grow, understanding root

608 development will help us engineer crops that are more robust to nutrient scarcities and environmental

609 extremes. The major pathway by which eudicot plants regulate their root architecture is through

610 modification of the position, spacing, density, and length of lateral roots. The stages of lateral root

611 development are regulated by distinct genetic circuitry. Every stage represents an opportunity for natural

612 and engineered modification of this developmental process. Molecular characterization of early stages of 
bioRxiv preprint doi: https://doi.org/10.1101/2020.10.02.324327; this version posted November 20,2020 . The copyright holder for this preprint (which was not certified by peer review) is the author/funder, who has granted bioRxiv a license to display the preprint in perpetuity. It is made available under aCC-BY-NC-ND 4.0 International license.

613 lateral root at single-cell resolution gives us a more comprehensive understanding of this fate decision and

614 the molecular pathways that tune it.

615

616 
Figure 1: Analysis of lateral root initiation using single-cell RNA-sequencing. A. Experimental design: Arabidopsis thaliana seedlings were grown vertically for 4 days post-germination (dpg) then rotated (or marked, in case of control) and grown for an additional eight or twenty hours. Protoplasts were prepared from microdissected root sections for single-cell RNA sequencing. B. UMAP of all 6658 cells colored by experiment. Cell type identities were assigned to each partition based on a set of marker genes. The cell type identities are indicated on the UMAP with the number of cells corresponding to each cell type. C. UMAP of pericycle specific cells, such as lateral root primordia (LRP), mature pericycle (MP), phloem pole pericycle (PPP), and xylem pole pericycle cells (XPP) colored by experiment. D. Expression pericycle-specific UMAPs of two DEGs between LRP and XPP. E. Scatter plot of the log2 fold change of average gene expression between XPP and LRP and the Mann Whitney Wilcoxon qvalue. DEGs are colored in red. A selection of GO Terms associated with DEGs are shown above the plot.

Figure 2. Validation experiments on chromatin modifier candidate genes. A. Heatmap (row-scaled) visualizing expression of candidate genes in the pericycle cell clusters from the single-cell library. Scale bar represents the z-score of the normalized expression values. B. Confocal microscopy images of candidate genes' transcriptional reporters in early stage lateral root primordia (left) and bright field image of corresponding primordia (right). C. Lateral root density of $\mathrm{J} 0121^{\mathrm{Col}}>>\mathrm{dCas} 9 \mathrm{R}$ transgenic lines of candidate genes. D. Proportion of total root length contributed by lateral roots of $\mathrm{J} 0121^{\mathrm{Col}}>>\mathrm{dCas} 9 \mathrm{R}$ transgenic lines of candidate genes. For $\mathrm{C}$ and $\mathrm{D}$, significance was determined by pairwise comparison with empty vector control and ANOVA. For each candidate gene, multiple independent transgenic lines have been analyzed; each colored line in the graph represents an individual line.

Figure 3. Validation experiments on cell cycle regulator candidate genes. A. Heatmap (row-scaled) visualizing expression of candidate genes in the pericycle cell clusters from the single-cell library. Scale bar represents the z-score of the normalized expression values. B. Confocal microscopy images of candidate genes' transcriptional reporters in early stage lateral root primordia (left) and bright field image of corresponding primordia (right). C. Lateral root density of $\mathrm{J} 0121^{\mathrm{Col}}>>\mathrm{dCas} 9 \mathrm{R}$ transgenic lines of candidate genes. D. Proportion of total root length contributed by lateral roots of $\mathrm{J} 0121^{\mathrm{Col}}>>\mathrm{dCas} 9 \mathrm{R}$ transgenic lines of candidate genes. For $\mathrm{C}$ and $\mathrm{D}$, significance was determined by pairwise comparison with empty vector control and ANOVA. For each candidate gene, multiple independent transgenic lines have been analyzed; each colored line in the graph represents an individual line.

Figure 4. Validation experiments on stemness candidate genes. A. Heatmap (row-scaled) visualizing expression of candidate genes in the pericycle cell clusters from the single-cell library. Scale bar represents the z-score of the normalized expression values. B. Confocal microscopy images of candidate genes' transcriptional reporters in early stage lateral root primordia (left) and bright field image of corresponding primordia (right). C. Lateral root density of $\mathrm{J} 0121^{\mathrm{Col}}>>\mathrm{dCas} 9 \mathrm{R}$ transgenic lines of candidate genes. D. Proportion of total root length contributed by lateral roots of $\mathrm{J} 0121^{\mathrm{Col}}>\mathrm{dCas} 9 \mathrm{R}$ transgenic lines of candidate genes. For $\mathrm{C}$ and $\mathrm{D}$, significance was determined by pairwise comparison with empty vector control and ANOVA. For each candidate gene, multiple independent transgenic lines have been analyzed; each colored line in the graph represents an individual line. 
Figure 5. Analysis of non-LRP cells in the single-cell library. A. Heatmap (row-scaled) of expression patterns of previously-identified LR-specifying genes in different cell clusters. B. Expression heatmap (row-scaled) of specific auxin-inducing and auxin-repressing genes in different stele cell clusters. C. UMAP of Cortex, Endodermis, and Lateral Root Responding Endodermis (LRE) cells. D. Expression UMAP of ORE1, a NAC transcription factor that promotes autophagy of endodermal cells overlying LRPs. E. Expression UMAP of AT8GA. F. Gene ontology of genes enriched in endodermis and LRE cell populations. The Venn diagram represents DEGs upregulated in endodermis in comparison to the cortex and upregulated in LRE in comparison to the cortex. A selection of GO terms for each of these sets of DEGs are shown.

Supplemental Figure 1. Marker gene expression profiles and stele cell UMAP. A. Heatmap (columnscaled) visualizing average normalized expression of marker genes in the columella cells, epidermis cells, cortex \& endodermis cells, and stele cells. Scale bar represents the z-score of the normalized expression values. B. Heatmap (column-scaled) visualizing average normalized expression of marker genes in different stele cell types. Scale bar represents the z-score of the normalized expression values. C. UMAP of stele cells colored by experiment. D. Fraction of xylem pole pericycle (XPP), lateral root primordia (LRP), mature pericycle (MP), and phloem pole pericycle (PPP) cells from each experiment. Mature Pericycle trajectory colored by pseudotime. B. UMAP of the XPP to LRP trajectory colored by pseudotime. C. Expression UMAP (XPP and Mature Pericycle cells) of DEGs identified in both trajectories (XPP to Mature Pericycle and XPP to LRP) and in only the XPP to Mature Pericycle trajectory. D. Expression UMAP (XPP and LRP cells) of DEGs identified in both trajectories and in only the XPP to LRP trajectory. E.. Heatmap (row-scaled) visualizing average normalized expression of genes identified as differentially expressed in the XPP to LRP trajectory. Scale bar represents the z-score of the normalized expression values. number of DEGs up in LRP and up in XPP are shown. All genes that were called in two or more methods were used for downstream analysis.

\section{Supplemental Figure 4. Comparison of XPP and LRP DEGs from the single-cell library to bulk} transcriptomes. A. Comparison to LRP-induced genes from Vanneste et al, 2005. B. Comparison to time-course analysis of lateral root initiation at nine and twenty-one hours post-bend from Voß et al, 2015. C. Comparison to auxin-induced and auxin-repressed genes in the root from Lewis et al, 2013. D. Comparison to ARF19-specific auxin-induced genes from Powers et al, 2019. E. Comparison to genes oscillating in phase and antiphase to auxin in the basal meristem during lateral root specification from Moreno-Risueno et al, 2010. F. Comparison to auxin-induced genes during early lateral root development from Ramakrishna et al, 2019. Each gene set from bulk transcriptomes is compared to the XPP and LRP DEGs with a size-adjusted Venn diagram. The number of genes in each mutually-exclusive area of each Venn diagram are specified. The values in purple and turquoise denote the hypergeometric distribution 
Supplemental Figure 5. Design of $\mathrm{J0121}^{\mathrm{Col}}>>$ dCas9R system to generate cell type-specific dCas9repressor mediated knockdown of candidate gene expression. A. $\mathrm{J} 0121^{\mathrm{Col}}$ is an enhancer trap line where the UAS-Gal4 system drives expression of GFP in the xylem pole pericycle cell file, visualized in confocal microscopy image and B. labeled in cartoons (in green). C. Top panel indicates the enhancer trap cassette in the $\mathrm{J} 0121^{\mathrm{Col}}$ and bottom panels is design of perturbation plasmids included up to three guide RNAs, tagged as location L1, L2, and L3, and a UAS promoter driving expression of dCas9repressor cassette. Perturbation plasmids with respective cloned guide RNAs were transformed into $\mathrm{J} 0121^{\mathrm{Col}}$ background to drive repression of target genes specifically in xylem pole pericycle cells. from T2 perturbation line seedlings were quantified for various lateral root developmental phenotypes using SmartRoot.

Supplemental Figure 7. Transcriptional reporters of chromatin regulator candidate genes in wild type and arf7arf19 roots. Fluorescent microscopy images of transgenic plant lines carrying transcriptional reporters of candidate genes in early stage lateral root primordia are shown in the large left-side image of each panel. Smaller images of the same transcriptional reporters in a region of the differentiated zone of the root without any developing primordia (above) and in the root apical meristem (below) are shown on the right in each panel. The same reporters in the same regions of the root are imaged in arf7arf19 mutant background plants on the right. The number of independent transgenic lines imaged per construct and the number of plants within each line that showed expression are reported at the bottom. The lower panel represents $1000 \mathrm{bp}$ upstream of the transcription start site for each gene, with auxin response elements (TGTC/GACA) highlighted in red. Yellow bars indicate CDSs from other genes. This panel was obtained from http://bar.utoronto.ca/cistome.

\section{Supplemental Figure 8. Transcriptional reporters of cell cycle candidate genes in wild type and} arf7arf19 roots. Fluorescent microscopy images of transgenic plant lines carrying transcriptional reporters of candidate genes in early stage lateral root primordia are shown in the large left-side image of each panel. Smaller images of the same transcriptional reporters in a region of the differentiated zone of the root without any developing primordia (above) and in the root apical meristem (below) are shown on the right in each panel. The same reporters in the same regions of the root are imaged in arf7arf19 mutant background plants on the right. The number of independent transgenic lines imaged per construct and the number of plants within each line that showed expression are reported at the bottom. The lower panel represents $1000 \mathrm{bp}$ upstream of the transcription start site for each gene, with auxin response elements (TGTC/GACA) highlighted in red. Yellow bars indicate CDSs from other genes. This panel was obtained from http://bar.utoronto.ca/cistome.

\section{Supplemental Figure 9. Transcriptional reporters of stemness candidate genes in wild type and} arf7arf19 roots. Fluorescent microscopy images of transgenic plant lines carrying transcriptional reporters of candidate genes in early stage lateral root primordia are shown in the large left-side image of each panel. Smaller images of the same transcriptional reporters in a region of the differentiated zone of the root without any developing primordia (above) and in the root apical meristem (below) are shown on the right in each panel. The same reporters in the same regions of the root are imaged in arf7arf19 mutant background plants on the right. The number of independent transgenic lines imaged per construct and the 
749 number of plants within each line that showed expression are reported at the bottom. The lower panel 750 represents $1000 \mathrm{bp}$ upstream of the transcription start site for each gene, with auxin response elements

751 (TGTC/GACA) highlighted in red. Yellow bars indicate CDSs from other genes. This panel was obtained

752 from http://bar.utoronto.ca/cistome.

754 Supplemental Figure 10. Marker gene expression profiles and experiment breakdown of cortex,

755 endodermis, and lateral root endodermis cells. A. Heatmap (column-scaled) visualizing average

756 normalized expression of marker genes in the cortex, endodermis, lateral root endodermis (LRE) cells. B.

757 Fraction of cortex, endodermis, and LRE cells from each experiment.

Supplementary Figure 11. DEG overlaps with different methods for Endodermis/Lateral Root Endodermis analyses A. Endodermis vs cortex comparison and B. LRE vs cortex comparison. For each ensemble of the Venn Diagram, the total number of DEGs, the number of DEGs up in Cortex and up in Endodermis (for A) and LRE (for B) are added to the diagram. UMAP of the endodermis to LRE trajectory colored by pseudotime. B. UMAP of the expression of gene sets that differed significantly as a function of pseudotime in the main endodermis branch and the LRE Branch. C. Expression UMAP of DRO1. D. Expression UMAPs of WRKY75 and PILS5. 
772 Author contributions: A.L., H.P.G., C.Q., J.T.C and J.L.N. designed the research; H.P.G., A.L., S.G., 773 J.C.C., J.E.Z., W.G. and J.T.C performed research; A.L., H.P.G., K. J-B., J.T.C and J.L.N. analyzed data; 774 and A.L., H.P.G., K. J-B. and J.L.N. wrote the manuscript.

\section{Acknowledgements}

777 We would like to thank members of the Nemhauser, Queitsch, Trapnell, Steinbrenner and Imaizumi 778 groups for helpful discussions and technical guidance. We are grateful for the generosity of Dr. Dolf 779 Weijers and his group in hosting A.L. to work on TMO6, as well as for Dr. Bert De Rybel's sharing of 780 TMO6 reporter lines. This work was supported by the National Institutes of Health (R01-GM107084;

781 J.L.N.; R01-GM079712, C.Q. and J.C.), the Howard Hughes Medical Institute Faculty Scholars Program 782 (J.L.N.), and the National Science Foundation (IOS-1748843; C.Q. and J.C.). A.L. was supported by an 783 NSF Graduate Research Fellowship (DGE-1256082), and S.G. was supported by an EMBO Postdoctoral 784 Award (ALTF 409-2019). 
bioRxiv preprint doi: https://doi.org/10.1101/2020.10.02.324327; this version posted November 20, 2020. The copyright holder for this preprint (which was not certified by peer review) is the author/funder, who has granted bioRxiv a license to display the preprint in perpetuity. It is made available under aCC-BY-NC-ND 4.0 International license.

787 


\section{Methods}

\section{Construction of plasmids}

Each reporter plasmid is composed of the selected promoter, the red fluorescent protein mScarlet with a nuclear localization tag (Bindels et al., 2017), and the rbcS terminator (Siligato et al., 2016). The three parts were assembled using golden gate assembly in the modified pGII-Hygr vector containing compatible Golden Gate sites (Weber et al., 2011). For each of the ten constructed reporters, the promoter sequence of the reporter corresponds to the DNA sequence in 5' of the start codon of the corresponding gene based on TAIR10 genome from http://plants.ensembl.org/. While aiming for a $2000 \mathrm{bp}$ length, the lengths of promoters are usually smaller to avoid coding sequences of other genes. The exact sequence and length of the selected promoter for each of the 10 genes can be found in supplementary material (Supplementary Data 2). The promoter sequence for the TMO6 reporters corresponds to the sequence used in a previous work from (Smet et al., 2019). The promoter sequences were amplified from purified Arabidopsis thaliana Col-0 genomic DNA using Q5 polymerase and with primer adding the specific golden gate spacer. After gel purification, each promoter part was cloned and sequence verified in a pBLUNT entry vector. Three part Golden Gate assembly was performed using the pBLUNT promoter plasmid, mScarlet, rbcS terminator to clone reporter plasmid.

For cell type specific knockdown mediated by $\mathrm{J} 0121^{\mathrm{Col}}>>\mathrm{dCas} 9 \mathrm{R}$, Gibson cloning was used to replace the egg specific promoter and Cas9 from pHEE401E (Wang et al., 2015) with UAS promoter and dCas9-TPL fusion (Khakhar et al., 2018). The resulting plasmid is used as starting point to clone two or three guide RNA against the promoters of selected gene/genes (identified using CHOP CHOP (Montague et al., 2014) ranging from -200 to +100 region from the annotated TSS) using PCR and golden gate strategy described in (Wang et al., 2015).

For all plant experiments, Arabidopsis seeds were sown on $0.5 \times$ LS $0.8 \%$ agar plates, stratified at $4^{\circ} \mathrm{C}$ for 2 days, and grown in continuous light conditions at $22^{\circ} \mathrm{C}$ for respective experimental design.

\section{Microdissection of root bend and protoplast isolation}

For lateral root induction assays, $\sim 150$ seedling for each timepoint and treatment were rotated $90^{\circ} 4$ days post-germination (dpg) or in the case of the control treatment, the primary root tip was marked at this time and the plates were not turned. On the day of single-cell library preparation first the protoplasting enzyme mix was prepared adapted from (Yoo et al., 2007). Briefly, $20 \mathrm{mM}$ MES (pH 5.7) containing 1.25\% (wt/vol) cellulase R10 (C224 PhytoTechnology Laboratories), 0.3\% (wt/vol) macerozyme R10 (M481 PhytoTechnology Laboratories,), $0.4 \mathrm{M}$ mannitol and $20 \mathrm{mM} \mathrm{KCl}$ was prepared and incubated in $55^{\circ} \mathrm{C}$ warm water bath for 10 minutes. Upon cooling to room temperature $\left(\sim 25^{\circ} \mathrm{C}\right), 10 \mathrm{mM} \mathrm{CaCl} 2,1-5$ and $0.1 \%$ BSA was added. Root bends (or marked region in no bend control) were microdissected using a scalpel at eight hours (control and eight hour treatment groups) and 20 hours (20 hour treatment group) post-bending, approximately $1 \mathrm{~mm}$ from the bend or mark in both directions. Using fine forceps dissected bend tissue was transferred into $30 \mathrm{~mm}$ dishes containing $1 \mathrm{~mL}$ of protoplasting enzyme mix and gently scored using a fresh scalpel to increase exposure of interior cell files to protoplasting enzymes. The plates were then flooded with $9 \mathrm{~mL}$ more protoplasting enzyme mix and incubated at room temperature for one 
hour with gentle shaking (75-80rpm). Protoplasting enzyme mix was filtered through $40 \mu \mathrm{m}$ cell strainer, transferred and centrifuged in $15 \mathrm{ml}$ conical tubes for five min at $500 \mathrm{~g}$. The supernatant was carefully removed and resuspended in $50 \mu 1$ protoplasting mix without enzymes. Cell number was determined by hemocytometer and density was adjusted to $\sim 1000$ cell $/ \mu \mathrm{L}$

Construction and selection of transgenic Arabidopsis thaliana lines $25 \mu \mathrm{g} / \mathrm{ml}$ Hygromycin B $+0.8 \%$ bacto-agar. Plates were stratified for two days, exposed to the light for six hours, and then grown in the dark for three days (Harrison et al., 2006). Hygromycin resistant seedlings were identified by their long hypocotyl, enlarged green leaves, and long root. Transformants were transferred on soil, and T2 seeds were collected.

\section{Lateral root bend assay and confocal microscopy}

For each reporter, one Col-0 T1 line representative of other characterized T1 lines was selected to perform lateral root bend essay. For each reporter, $20 \mathrm{~T} 2$ seeds of the corresponding $\mathrm{T} 1$ line were placed on $0.5 \mathrm{LS}+0.8 \%$ bacto-agar plate following a specific pattern to avoid seedling collision during the lateral root bend essay. The plate was stratified during 120 hours, grown vertically for 96 hours at $22^{\circ} \mathrm{C}$, rotated $90^{\circ} \mathrm{C}$ while keeping vertically and grown for an additional 20 hours.

\section{Confocal microscopy of reporter lines at root bends}

Seedlings were fixed at $4 \mathrm{dpg}+20$ hours using $4 \%$ formaldehyde using vacuum infiltration followed by cleared using ClearSee solution (Kurihara et al., 2015). Fixed and cleared seedlings were mounted on microscopic slides using 50\% glycerol and parafilm edges to avoid coverslips pressing on the root. Seedlings were imaged at the bend region using a SP5 confocal microscope. Images were processed using FIJI.

\section{Comparison between Col-0 and arf7arf19 lines}

To perform comparative imaging of Col-0 and arf7arf19 reporter lines, seeds of selected T1 lines for both Col- 0 and arf7arf19 reporter lines were placed on the same $0.5 \mathrm{LS}+0.8$ phytoagar plate. The selected Col0 and arf7arf19 lines for each reporter is specified below the microscope images of supplemental figure 7 to 9 as being highlighted in bold. Plates were stratified for 2 days, and grown vertically at $22^{\circ} \mathrm{C}$ for 10 days. Then, seedlings were imaged using a Leica DMI 3000B microscope at the root tip region, at the region above the root tip corresponding to the initiation of root hair and at the lateral root initiation region. As the arf7arf19 line does not develop lateral roots, the theoretical lateral root initiation region is identified by identifying a lateral root primordium in the Col-0 seedling and imaging at a similar region.

\section{Lateral root phenotypes of repression lines}

For cell type specific knockdown mediated by J012 ${ }^{\mathrm{Col}}>>\mathrm{dCas} 9 \mathrm{R}$ we leveraged an established GAL4UAS system (Laplaze et al., 2005) of enhancer trap line J0121. We backcrossed the J0121 line, made in the $\mathrm{C} 24$ background, eight times into the Col-0 background to produce a strain we refer to as $\mathrm{J} 0121^{\mathrm{Col}}$. We confirmed that $\mathrm{J} 0121^{\mathrm{Col}}$ retained strong GFP expression in xylem pole pericycle and exhibited Col-0like root growth dynamics. Transformants were selected as described above and T2 seeds for at least 10 lines were collected. T2 seeds were grown vertically for $10 \mathrm{dpg}$ in $100 \mathrm{~mm}$ square plate on $0.8 \%$ bacto agar 
872

873

874

875

876

877

878

879

880

881

882

883

884

885

886

887

888

889

890

891

892

893

894

895

896

897

898

899

900

901

902

903

904

905

906

907

908

909

910

911

912

913

914

and were scanned on a flatbed scanner (Epson America, Long Beach, CA) for phenotyping. Since the T2 generation is a segregating population for the transformed plasmid, seedlings were genotyped for the presence of vector backbone to identify positive seeding. Roots for positive seedlings were traced using ImageJ and SmartRoot plugin (Lobet et al., 2011) and analyzed and plotted using R package archiDART (Delory et al., 2016) package plot were generated using ggplot2. Density was measured as the total number of lateral roots divided by the length of the primary root. Proportion of lateral root length was measured as the summed length of all lateral roots divided by the summed length of all lateral roots and the primary root length.

\section{Single-cell RNA-sequencing Protocol}

Single-cell RNA-Seq was performed using the 10X scRNA-Seq platform, the Chromium Single Cell Gene Expression Solution (10X Genomics). Two replicates were produced for each timepoint of the experiment for a total of six samples. We also generated two replicates from a transgenic plant line that slows the rate of degradation of IAA14 (Guseman et al., 2015), dissecting root bends in this line twenty hours after bending. This line shows delayed lateral root development, and we initially thought to compare its transcriptomes to our wild type treatment groups. Unfortunately, one of the replicates of this line failed at the $10 \mathrm{X}$ droplet-binding stage, so we did not obtain the same number cells from this treatment group as from our other groups. Consequently, we excluded these cells from further analysis.

\section{Estimating Gene Expression in Individual Cells}

Single-cell RNA-sequencing reads were sequenced using an Illumina NextSeq 500 and then mapped to the TAIR10 Arabidopsis genome using the software Cellranger (v.3.0.1). Cellranger produces a matrix of UMI counts where each row is a gene and each column represents a cell. The ARAPORT gene annotation was used. For the analysis, reads from two 00 hour replicates, two 08 hour replicates, and two 20 hour replicates were aggregated using the aggr command in cellranger to normalize to an equivalent number of mean reads per cell across samples. This resulted in a mean of 14,516 reads per cell, a median of 1,411 genes per cell, and a median of 2,873 UMIs per cell.

\section{Running Monocle 3: Dimensionality Reduction, and Cell Clustering}

The filtered output of the Cellranger pipeline (../outs/filtered_gene_bc_matrices_mex/) was parsed into R (v. 3.5.0). Particularly the matrix.mtx file was parsed using the readMM() function from the Matrix package (https://cran.r-project.org/web/packages/Matrix/Matrix.pdf), and the barcodes.tsv file and the genes.tsv file were parsed using the read.table() function. Genes that were expressed in less than 10 cells were removed from the analysis. In addition, the 346 genes induced due to protoplast generation process were also removed from the analysis (Birnbaum et al., 2003). The barcodes table was updated to label cells by Sample Number and Experiment. Finally the expression matrix, the barcode table, and the gene table were converted into a CellDataSet (CDS) using the new_cell_data_set() function in Monocle 3 (cole-trapnell-lab/monocle3, 2020) (v. 0.1.2; https://cole-trapnell-lab.github.io/monocle3/)

All Monocle 3 analysis was performed on a High Performance Computing cluster using 128 GB of RAM spread across eight cores. We visualized cell clusters and trajectories using the standard Monocle workflow. Monocle internally handles all normalization needed for dimensionality reduction, visualization, and differential expression. The CDS was normalized and pre-processed using the preprocess_cds() function with the following parameters: 
num_dim $=100$,

916 method="PCA",

917 norm_method="log",

918 scaling=T,

919 residual_model_formula_str=" $~$ Sample_Number"

Preprocessing involves reducing the dimensionality of the data (the number of genes) using principal component analysis (PCA). Here, we retain the first 100 PCs for further dimensionality reduction, in addition we reduce batch effect across samples. Then, the PCA matrix was used to initialize a nonlinear manifold learning algorithm implemented in Monocle 3 called Uniform Manifold Approximation and Projection (UMAP) (McInnes et al., 2018). This allows us to visualize the data into two or three dimensions. Specifically, we projected the data onto two dimensions using the reduce_dimension() function using the following parameters:

reduction_method="UMAP",

930 preprocess_method="PCA",

931 umap.metric $=$ "cosine",

932 umap.min_dist $=0.1$,

933 umap.n_neighbors $=15 \mathrm{~L}$,

934 umap.nn_method="annoy",

935 umap.fast_sgd=F

Next, cells were clustered into partitions using PhenoGraph (Levine et al., 2015) and into clusters using the Leidan community detection algorithm (Traag et al., 2019) with the cluster_cells() function using the following parameters:

948 This resulted in 5 cell partitions, and 43 cell clusters. Next, for each cell partition, a cell trajectory was 949 drawn atop the projection using Monocle's reversed graph embedding algorithm, which is derived from SimplePPT (Mao et al., 2017) using the learn_graph() function using the following parameters: use_partition $=\mathrm{T}$, close_loop $=\mathrm{F}$, learn_graph_control=list(prune_graph=T)

To further analyze the partition we annotated as stele, those cells were reclustered together and were reanalyzed using Monocle 3 as previously described except during preprocessing, instead of performing PCA on all the genes, PCA was performed on just a set of stele cell marker genes reported earlier (Mao et 
al., 2017). Specifically the "use_genes" option was used in the preprocess_cds() function, and a list of gene names was provided. Lastly, cells were clustered using the cluster_cells() function, and the "resolution" parameter was set to 0.001 . This produced 3 partitions, and 7 clusters.

To further analyze the clusters we annotated as Phloem Pole Pericycle, Mature Pericycle, Xylem Pole Pericycle, and Lateral Root Primordia, those cells were reclustered together and were reanalyzed using Monocle 3 as previously described except during preprocessing, instead of performing PCA on all the genes, PCA was performed on just a set of stele cell marker genes reported in (Brady et al., 2007). Again, Specifically the "use_genes" option was used in the preprocess_cds() function, and a list of gene names was provided. Next, the data was reduced onto two dimensions using the reduce dimension function but the "umap.min_dist" parameter was set to 0.01. Afterwards cell clusters were called as before using the cluster_cells() function except the "resolution" parameter was set to 0.0005 . Next a cell trajectory was created using the learn_graph() function. Finally cell clusters were recalled using the cluster_cells() function except the "resolution" parameter was set to 0.001 . This produced 1 partition and 4 clusters. To further analyze the partition we annotated as Cortex and Endodermis, those cells were reclustered together and were reanalyzed using Monocle 3 as previously described except during preprocessing, instead of performing PCA on all the genes, PCA was performed on just a set of cortex and endodermis cell marker genes reported in (Brady et al., 2007). This produced 2 partitions and 15 clusters.

\section{Estimating Doublets} (Wolock et al., 2019). Using python 3.5, Scrublet was run using default settings as described by the example tutorial that is available as a Python notebook (https://github.com/AllonKleinLab/scrublet/blob/master/examples/scrublet_basics.ipynb). The only significant change was that expected double rate was set to 0.1 ; in the tutorial it is 0.06 .

\section{Assigning Cell Types}

A set of known marker genes derived from earlier studies using green fluorescent protein (GFP) marker lines of the Arabidopsis root were used to identify cell types (Brady et al., 2007; Cartwright et al., 2009). The average gene expression of each marker set was used to assign cell types to cells, with cells being assigned the cell type it had the highest average expression

\section{Calling Differentially Expressed Genes: Xylem Pole Pericycle vs. Lateral Root Primordia}

Differentially expressed genes between the cluster of cells labeled Xylem Pole Pericycle and the cluster of cells labeled Lateral Root Primordia were called using three different approaches.

The first approach involved running a generalized linear model to predict the average log express of each gene as a function of the cell type label. This was done using a subsetted CDS containing only the Xylem Pole Pericycle cells and the Lateral Root Primordia cells, and the Monocle 3 function fit_models() with the following parameters:

model_formula_str = " cell_type", expression_family="negbinomial", clean_model $=\mathrm{T}$ 
where "cell_type" is a column in the dataframe returned by the colData() function that describes the cell type label associated with a cell/barcode. Using an FDR cutoff of 0.1, 1204 genes were called as differentially expressed between Xylem Pole Pericycle and Lateral Root Primordia. Of these, 424 were more highly expressed in Xylem Pole Pericycle, and 780 were more highly expressed in Lateral Root Primordia.

The second approach involved using the Mann-Whitney-Wilcoxon test to determine if the rank-sum of the normalized expression values for each gene differed between the Xylem Pole Pericycle population and the Lateral Root Primordia population. Mann-Whitney-Wicoxon test p-values were adjusted for multiple test comparisons using the Benjamini-Hochberg procedure via the R function p.adjust() from the stats package. Normalized expression values were calculated by taking the UMI matrix, obtained using Monocle 3's counts() function and dividing by the size factors of each cell using Monocle 3's size_factors() function. Using an adjusted p-value cutoff of 0.0001, 2088 genes were called as differentially expressed with 604 genes more highly expressed in Xylem Pole Pericycle and 1484 genes more highly expressed in Lateral Root Primordia.

The last approach involved using the analysis tool Vision. The normalised expression matrix for only XPP and LRP cell clusters was exported from Monocle. The gene signature of pericycle cell population from (Parizot et al., 2012) were used for running Vision() and analyse() function. LRP cell population was selected in browser view mode to identify DEG against XPP population. Vision identified 4900 DEGs using an FDR of less than 0.05 .

\section{Pseudotime Analysis: Xylem Pole Pericycle Cells Development}

Pseudotime analysis was performed on two subsetted CDSs, one containing only Xylem Pole Pericycle cells and Mature Pericycle cells, and the other containing only Xylem Pole Pericycle cells and Lateral Root Primordia cells. Cells in both CDSs were assigned a pseudotime on the cell trajectory using Monocle 3's order_cells() function with the Xylem Pole Pericycle serving as the root of the trajectory. Genes whose expression changed as a function of pseudotime were identified using a generalized linear model. This was done on both CDSs using the fit_models() function and the following parameters:

model_formula_str $=$ " pseudotime", expression_family="negbinomial", clean_model=T Using an FDR cutoff of 0.1, 1394 genes were identified as changing as a function of pseudotime in the CDS containing only Xylem Pole Pericycle cells and Mature Pericycle cells, and 1014 genes were identified as changing as a function of pseudotime in the CDS containing only Xylem Pole Pericycle cells and Lateral Root Primordia cells with an overlap of 510 genes.

\section{Calling Differential Expressed Genes: Endodermis vs. Lateral Root Primodia Responding Endodermis} As previously described, a generalized linear model was used to identify differentially expressed genes between the cluster of cells labeled Endodermis, and the cluster of cells labeled Lateral Root Primodia Responding Endodermis. Using an FDR cutoff of 0.1, 1251 genes were identified as differentially expressed, with 748 genes being more expressed in Endodermis and 503 genes being more expressed in 
Lateral Root Endodermis. To identify additional DEGs, the MMW test was performed comparing Endodermis to Cortex and Lateral Root Endodermis to Cortex. other containing only Endodermis below the branch point, and Lateral Root Primodia Responding Endodermis. As previously described, cells were assigned a pseudotime along the cell trajectory with the Endodermis cells below the branch point serving as the root. As previously described, a generalized linear model was used to identify differentially expressed genes as a function of pseudotime. Using an FDR cutoff of 0.1, 2063 genes were identified in the CDS with only Endodermis, and 2079 genes were identified in the CDS with only Endodermis and LRP Responding Endodermis with an overlap of 2060 genes.

GO Term Enrichment Analysis methods were used for analysis. All genes in the Arabidopsis genome were used as a background. complete annotation data set for biological process, molecular function, and cellular component GO terms were used for analysis.

\section{Accession Numbers}

1068

\section{Supplementary Data files}

1072

1073 sheet and GO Terms $\mathrm{J} 0121^{\mathrm{Col}}>>$ dCas9R transgenic lines 


\section{Parsed Citations}

Beeckman, T., Burssens, S., and Inzé, D. (2001). The peri-cell-cycle in Arabidopsis. J. Exp. Bot. 52: 403-411.

Google Scholar: Author Only Title Only Author and Title

Berger, F., Hung, C.-Y., Dolan, L., and Schiefelbein, J. (1998). Control of Cell Division in the Root Epidermis ofArabidopsis thaliana. Dev. Biol. 194: 235-245.

Google Scholar: Author Only Title Only Author and Title

Bindels, D.S., Haarbosch, L., van Weeren, L., Postma, M., Wiese, K.E., Mastop, M., Aumonier, S., Gotthard, G., Royant, A, Hink, M.A, and Gadella, T.W.J. (2017). mScarlet: a bright monomeric red fluorescent protein for cellular imaging. Nat. Methods 14: 53-56.

Google Scholar: Author Only Title Only Author and Title

Birnbaum, K., Shasha, D.E., Wang, J.Y., Jung, J.W., Lambert, G.M., Galbraith, D.W., and Benfey, P.N. (2003). Agene expression map of the Arabidopsis root. Science 302: 1956-1960.

Google Scholar: Author Only Title Only Author and Title

Brady, S.M., Orlando, D.A, Lee, J.-Y., Wang, J.Y., Koch, J., Dinneny, J.R., Mace, D., Ohler, U., and Benfey, P.N. (2007). A high-resolution root spatiotemporal map reveals dominant expression patterns. Science 318: 801-806.

Google Scholar: Author Only Title Only Author and Title

Brenner, W.G., Leuendorf, J.E., Cortleven, A, Martin, L.B.B., Schaller, H., and Schmülling, T. (2017). Analysis of CFB, a cytokininresponsive gene of Arabidopsis thaliana encoding a novel F-box protein regulating sterol biosynthesis. J. Exp. Bot. 68: 2769-2785.

Google Scholar: Author Only Title Only Author and Title

Briggs, G.C., Mouchel, C.F., and Hardtke, C.S. (2006). Characterization of the Plant-Specific BREVS RADIX Gene Family Reveals Limited Genetic Redundancy Despite High Sequence Conservation. Plant Physiol. 140: 1306-1316.

Google Scholar: Author Only Title Only Author and Title

Cao, J., Spielmann, M., Qiu, X., Huang, X., Ibrahim, D.M., Hill, AJ., Zhang, F., Mundlos, S., Christiansen, L., Steemers, F.J., Trapnell, C., and Shendure, J. (2019). The single-cell transcriptional landscape of mammalian organogenesis. Nature 566: 496-502.

Google Scholar: Author Only Title Only Author and Title

Cartwright, D.A, Brady, S.M., Orlando, D.A, Sturmfels, B., and Benfey, P.N. (2009). Reconstructing spatiotemporal gene expression data from partial observations. Bioinforma. Oxf. Engl. 25: 2581-2587.

Google Scholar: Author Only Title Only Author and Title

Chen, X., Lu, L., Qian, S., Scalf, M., Smith, L.M., and Zhong, X. (2018). Canonical and Noncanonical Actions of Arabidopsis Histone

Deacetylases in Ribosomal RNAProcessing. Plant Cell 30: 134-152.

Google Scholar: Author Only Title Only Author and Title

Chitwood, D.H. and Topp, C.N. (2015). Revealing plant cryptotypes: defining meaningful phenotypes among infinite traits. Curr. Opin. Plant Biol. 24: 54-60.

Google Scholar: Author Only Title Only Author and Title

Clough, S.J. and Bent, AF. (1998). Floral dip: a simplified method for Agrobacterium -mediated transformation of Arabidopsis thaliana.

Plant J. 16: 735-743.

Google Scholar: Author Only Title Only Author and Title

cole-trapnell-lab/monocle3 (2020). (cole-trapnell-lab).

De Rybel, B. et al. (2010). ANovel Aux/IAA28 Signaling Cascade Activates GATA23-Dependent Specification of Lateral Root Founder

Cell Identity. Curr. Biol. 20: 1697-1706.

Google Scholar: Author Only Title Only Author and Title

De Smet, l. et al. (2007). Auxin-dependent regulation of lateral root positioning in the basal meristem of Arabidopsis. Dev. Camb. Engl. 134: 681-690.

Google Scholar: Author Only Title Only Author and Title

Decaestecker, W., Buono, R.A, Pfeiffer, M.L., Vangheluwe, N., Jourquin, J., Karimi, M., Van Isterdael, G., Beeckman, T., Nowack, M.K., and Jacobs, T.B. (2019). CRISPR-TSKO: A Technique for Efficient Mutagenesis in Specific Cell Types, Tissues, or Organs in

Arabidopsis. Plant Cell 31: 2868-2887.

Google Scholar: Author Only Title Only Author and Title

Delory, B.M., Baudson, C., Brostaux, Y., Lobet, G., du Jardin, P., Pagès, L., and Delaplace, P. (2016). archiDART: an R package for the automated computation of plant root architectural traits. Plant Soil 398: 351-365.

Google Scholar: Author Only Title Only Author and Title

DeTomaso, D., Jones, M.G., Subramaniam, M., Ashuach, T., Ye, C.J., and Yosef, N. (2019). Functional interpretation of single cell similarity maps. Nat. Commun. 10: 4376.

Google Scholar: Author Only Title Only Author and Title

Devaiah, B.N., Karthikeyan, AS., and Raghothama, K.G. (2007). WRKY75 transcription factor is a modulator of phosphate acquisition 

available under aCC-BY-NC-ND 4.0 International license.

and root development in Arabidopsis. Plant Physiol. 143: 1789-1801.

Google Scholar: Author Only Title Only Author and Title

Ditengou, F.A, Teale, W.D., Kochersperger, P., Flittner, K.A, Kneuper, I., Graaff, E. van der, Nziengui, H., Pinosa, F., Li, X., Nitschke, R., Laux, T., and Palme, K. (2008). Mechanical induction of lateral root initiation in Arabidopsis thaliana. Proc. Natl. Acad. Sci. 105: 18818-18823.

Google Scholar: Author Only Title Only Author and Title

Du, Y. and Scheres, B. (2017). PLETHORA transcription factors orchestrate de novo organ patterning during Arabidopsis lateral root outgrowth. Proc. Natl. Acad. Sci. 114: 11709-11714.

Google Scholar: Author Only Title Only Author and Title

Dubrovsky, J.G., Gambetta, G.A, Hernández-Barrera, A, Shishkova, S., and González, I. (2006). Lateral root initiation in Arabidopsis: developmental window, spatial patterning, density and predictability. Ann. Bot. 97: 903-915.

Google Scholar: Author Only Title Only Author and Title

Escamez, S., André, D., Sztojka, B., Bollhöner, B., Hall, H., Berthet, B., Voß, U., Lers, A, Maizel, A, Andersson, M., Bennett, M., and Tuominen, H. (2020). Cell Death in Cells Overlying Lateral Root Primordia Facilitates Organ Growth in Arabidopsis. Curr. Biol. CB 30: 455-464.e7.

Google Scholar: Author Only Title Only Author and Title

Fitter, AH. (1987). An Architectural Approach to the Comparative Ecology of Plant Root Systems. New Phytol. $106:$ 61-77.

Google Scholar: Author Only Title Only Author and Title

Galinha, C., Hofhuis, H., Luijten, M., Willemsen, V., Blilou, I., Heidstra, R., and Scheres, B. (2007). PLETHORA proteins as dosedependent master regulators of Arabidopsis root development. Nature 449: 1053-1057.

Google Scholar: Author Only Title Only Author and Title

Goh, T. et al. (2019). Lateral root initiation requires the sequential induction of transcription factors LBD16 and PUCHI in Arabidopsis thaliana. New Phytol. 224: 749-760.

Google Scholar: Author Only Title Only Author and Title

Goh, T., Joi, S., Mimura, T., and Fukaki, H. (2012). The establishment of asymmetry in Arabidopsis lateral root founder cells is regulated by LBD16/ASL18 and related LBD/ASL proteins. Development 139: 883-893.

Google Scholar: Author Only Title Only Author and Title

Guo, J. and Chen, J.-G. (2008). RACK1 genes regulate plant development with unequal genetic redundancy in Arabidopsis. BMC Plant Biol. 8: 108.

Google Scholar: Author Only Title Only Author and Title

Guseman, J.M., Hellmuth, A, Lanctot, A, Feldman, T.P., Moss, B.L., Klavins, E., Calderón Villalobos, L.I.A, and Nemhauser, J.L. (2015). Auxin-induced degradation dynamics set the pace for lateral root development. Dev. Camb. Engl. 142: 905-909.

Google Scholar: Author Only Title Only Author and Title

Guseman, J.M., Webb, K., Srinivasan, C., and Dardick, C. (2017). DRO1 influences root system architecture in Arabidopsis and Prunus species. Plant J. Cell Mol. Biol. 89: 1093-1105.

Google Scholar: Author Only Title Only Author and Title

Harrison, S.J., Mott, E.K., Parsley, K., Aspinall, S., Gray, J.C., and Cottage, A (2006). A rapid and robust method of identifying transformed Arabidopsis thaliana seedlings following floral dip transformation. Plant Methods 2: 19.

Google Scholar: Author Only Title Only Author and Title

Himanen, K., Boucheron, E., Vanneste, S., de Almeida Engler, J., Inzé, D., and Beeckman, T. (2002). Auxin-Mediated Cell Cycle Activation during Early Lateral Root Initiation. Plant Cell 14: 2339-2351.

Google Scholar: Author Only Title Only Author and Title

Himanen, K., Vuylsteke, M., Vanneste, S., Vercruysse, S., Boucheron, E., Alard, P., Chriqui, D., Montagu, M.V., Inzé, D., and Beeckman, T. (2004). Transcript profiling of early lateral root initiation. Proc. Natl. Acad. Sci. 101: 5146-5151.

Google Scholar: Author Only Title Only Author and Title

Hu, X. and Xu, L. (2016). Transcription Factors WOX11/12 Directly Activate WOX5/7 to Promote Root Primordia Initiation and Organogenesis. Plant Physiol. 172: 2363-2373.

Google Scholar: Author Only Title Only Author and Title

Jean-Baptiste, K., McFaline-Figueroa, J.L., Alexandre, C.M., Dorrity, M.W., Saunders, L., Bubb, K.L., Trapnell, C., Fields, S., Queitsch, C., and Cuperus, J.T. (2019). Dynamics of Gene Expression in Single Root Cells of Arabidopsis thaliana. Plant Cell 31: $993-1011$.

Google Scholar: Author Only Title Only Author and Title

Jeon, J., Cho, C., Lee, M.R., Van Binh, N., and Kim, J. (2016). CYTOKININ RESPONSE FACTOR2 (CRF2) and CRF3 Regulate Lateral Root Development in Response to Cold Stress in Arabidopsis. Plant Cell 28: 1828-1843.

Google Scholar: Author Only Title Only Author and Title

Khakhar, A, Leydon, AR., Lemmex, AC., Klavins, E., and Nemhauser, J.L. (2018). Synthetic hormone-responsive transcription factors can monitor and re-program plant development. eLife 7. 
Khan, M.A, Gemenet, D.C., and Villordon, A (2016). Root System Architecture and Abiotic Stress Tolerance: Current Knowledge in Root and Tuber Crops. Front. Plant Sci. 7.

Google Scholar: Author Only Title Only Author and Title

Kim, J., Kim, J.H., Richards, E.J., Chung, K.M., and Woo, H.R. (2014). Arabidopsis VM Proteins Regulate Epigenetic Silencing by Modulating DNA Methylation and Histone Modification in Cooperation with MET1. Mol. Plant 7: 1470-1485.

Google Scholar: Author Only Title Only Author and Title

Kurihara, D., Mizuta, Y., Sato, Y., and Higashiyama, T. (2015). ClearSee: a rapid optical clearing reagent for whole-plant fluorescence imaging. Dev. Camb. Engl. 142: 4168-4179.

Google Scholar: Author Only Title Only Author and Title

Lanctot, A, Taylor-Teeples, M., Oki, E.A, and Nemhauser, J.L. (2020). Specificity in Auxin Responses Is Not Explained by the Promoter Preferences of Activator ARFs. Plant Physiol. 182: 1533-1536.

Google Scholar: Author Only Title Only Author and Title

Laplaze, L., Parizot, B., Baker, A, Ricaud, L., Martinière, A, Auguy, F., Franche, C., Nussaume, L., Bogusz, D., and Haseloff, J. (2005). GAL4-GFP enhancer trap lines for genetic manipulation of lateral root development in Arabidopsis thaliana. J. Exp. Bot. 56: $2433-2442$. Google Scholar: Author Only Title Only Author and Title

Lavenus, J. et al. (2015). Inference of the Arabidopsis Lateral Root Gene Regulatory Network Suggests a Bifurcation Mechanism That Defines Primordia Flanking and Central Zones[OPEN]. Plant Cell 27: 1368-1388.

Google Scholar: Author Only Title Only Author and Title

Levine, J.H. et al. (2015). Data-Driven Phenotypic Dissection of AML Reveals Progenitor-like Cells that Correlate with Prognosis. Cell 162: 184-197.

Google Scholar: Author Only Title Only Author and Title

Lewis, D.R., Olex, AL., Lundy, S.R., Turkett, W.H., Fetrow, J.S., and Muday, G.K. (2013). AKinetic Analysis of the Auxin Transcriptome

Reveals Cell Wall Remodeling Proteins That Modulate Lateral Root Development in Arabidopsis. Plant Cell 25: $3329-3346$.

Google Scholar: Author Only Title Only Author and Title

Li, H., Torres-Garcia, J., Latrasse, D., Benhamed, M., Schilderink, S., Zhou, W., Kulikova, O., Hirt, H., and Bisseling, T. (2017). PlantSpecific Histone Deacetylases HDT1/2 Regulate GIBBERELLIN 2-OXIDASE2 Expression to Control Arabidopsis Root Meristem Cell Number[OPEN]. Plant Cell 29: 2183-2196.

Google Scholar: Author Only Title Only Author and Title

Lobet, G., Pagès, L., and Draye, X. (2011). ANovel Image-Analysis Toolbox Enabling Quantitative Analysis of Root System

Architecture1[W][OA]. Plant Physiol. 157: 29-39.

Google Scholar: Author Only Title Only Author and Title

Luo, M., Cheng, K., Xu, Y., Yang, S., and Wu, K. (2017). Plant Responses to Abiotic Stress Regulated by Histone Deacetylases. Front. Plant Sci. 8.

Google Scholar: Author Only Title Only Author and Title

Lynch, J. (1995). Root Architecture and Plant Productivity. Plant Physiol. 109: 7-13.

Google Scholar: Author Only Title Only Author and Title

Malamy, J.E. and Benfey, P.N. (1997). Organization and cell differentiation in lateral roots of Arabidopsis thaliana. Development 124: 3344.

Google Scholar: Author Only Title Only Author and Title

Mao, Q., Wang, L., Tsang, I.W., and Sun, Y. (2017). Principal Graph and Structure Learning Based on Reversed Graph Embedding. IEEE Trans. Pattern Anal. Mach. Intell. 39: 2227-2241.

Google Scholar: Author Only Title Only Author and Title

Marhavý, P., Montesinos, J.C., Abuzeineh, A, Van Damme, D., Vermeer, J.E.M., Duclercq, J., Rakusová, H., Nováková, P., Friml, J., Geldner, N., and Benková, E. (2016). Targeted cell elimination reveals an auxin-guided biphasic mode of lateral root initiation. Genes Dev. 30: 471-483.

Google Scholar: Author Only Title Only Author and Title

Marhavý, P., Vanstraelen, M., De Rybel, B., Zhaojun, D., Bennett, M.J., Beeckman, T., and Benková, E. (2013). Auxin reflux between the endodermis and pericycle promotes lateral root initiation. EMBO J. 32: 149-158.

Google Scholar: Author Only Title Only Author and Title

Marin, E., Jouannet, V., Herz, A, Lokerse, AS., Weijers, D., Vaucheret, H., Nussaume, L., Crespi, M.D., and Maizel, A (2010). miR390, Arabidopsis TAS3 tasiRNAs, and Their AUXIN RESPONSE FACTOR Targets Define an Autoregulatory Network Quantitatively Regulating Lateral Root Growth. Plant Cell 22: 1104-1117.

Google Scholar: Author Only Title Only Author and Title

Mason, M.G., Mathews, D.E., Argyros, D.A, Maxwell, B.B., Kieber, J.J., Alonso, J.M., Ecker, J.R., and Schaller, G.E. (2005). Multiple type- 
bioRxiv preprint doi: https://doi.org/10.1101/2020.10.02.324327; this version posted November $20,2020$. The copyright holder for this preprint (which was not certified by peer review) is the author/funder, who has granted bioRxiv a license to display the preprint in perpetuity. It is made available under aCC-BY-NC-ND 4.0 International license.

$B$ response regulators mediate cytokinin signal transduction in Arabidopsis. Plant Cell 17: 3007-3018.

Google Scholar: Author Only Title Only Author and Title

McInnes, L., Healy, J., Saul, N., and Großberger, L. (2018). UMAP: Uniform Manifold Approximation and Projection. J. Open Source Softw. 3: 861.

Google Scholar: Author Only Title Only Author and Title

Mi, H., Muruganujan, A, Ebert, D., Huang, X., and Thomas, P.D. (2019). PANTHER version 14: more genomes, a new PANTHER GO-slim and improvements in enrichment analysis tools. Nucleic Acids Res. 47: D419-D426.

Google Scholar: Author Only Title Only Author and Title

Miyashima, S. et al. (2019). Mobile PEAR transcription factors integrate positional cues to prime cambial growth. Nature 565: 490-494.

Google Scholar: Author Only Title Only Author and Title

Montague, T.G., Cruz, J.M., Gagnon, J.A, Church, G.M., and Valen, E. (2014). CHOPCHOP: a CRISPR/Cas9 and TALEN web tool for genome editing. Nucleic Acids Res. 42: W401-W407.

Google Scholar: Author Only Title Only Author and Title

Moreno-Risueno, M.A, Van Norman, J.M., Moreno, A, Zhang, J., Ahnert, S.E., and Benfey, P.N. (2010). Oscillating gene expression determines competence for periodic Arabidopsis root branching. Science 329: 1306-1311.

Google Scholar: Author Only Title Only Author and Title

Muroyama, A, Gong, Y., and Bergmann, D.C. (2020). Opposing, Polarity-Driven Nuclear Migrations Underpin Asymmetric Divisions to Pattern Arabidopsis Stomata. Curr. Biol. CB.

Google Scholar: Author Only Title Only Author and Title

Murphy, E. et al. (2016). RALFL34 regulates formative cell divisions in Arabidopsis pericycle during lateral root initiation. J. Exp. Bot. 67: 4863-4875.

Google Scholar: Author Only Title Only Author and Title

Okushima, Y., Fukaki, H., Onoda, M., Theologis, A, and Tasaka, M. (2007). ARF7 and ARF19 Regulate Lateral Root Formation via Direct Activation of LBD/ASL Genes in Arabidopsis. Plant Cell 19: 118-130.

Google Scholar: Author Only Title Only Author and Title

Ou, Y. et al. (2016). RGF1 INSENSITIVE 1 to 5, a group of LRR receptor-like kinases, are essential for the perception of root meristem growth factor 1 in Arabidopsis thaliana. Cell Res. 26: 686-698.

Google Scholar: Author Only Title Only Author and Title

Parizot, B., Roberts, I., Raes, J., Beeckman, T., and De Smet, I. (2012). In silico analyses of pericycle cell populations reinforce their relation with associated vasculature in Arabidopsis. Philos. Trans. R. Soc. Lond. B. Biol. Sci. 367: 1479-1488.

Google Scholar: Author Only Title Only Author and Title

Porco, S. et al. (2016). Lateral root emergence in Arabidopsis is dependent on transcription factor LBD29 regulation of auxin influx carrier LAX3. Development 143: 3340-3349.

Google Scholar: Author Only Title Only Author and Title

Powers, S.K. et al. (2019). Nucleo-cytoplasmic Partitioning of ARF Proteins Controls Auxin Responses in Arabidopsis thaliana. Mol. Cell 76: 177-190.e5.

Google Scholar: Author Only Title Only Author and Title

Qiu, X., Mao, Q., Tang, Y., Wang, L., Chawla, R., Pliner, H.A, and Trapnell, C. (2017). Reversed graph embedding resolves complex single-cell trajectories. Nat. Methods 14: 979-982.

Google Scholar: Author Only Title Only Author and Title

Ramakrishna, P. et al. (2019). EXPANSIN A1-mediated radial swelling of pericycle cells positions anticlinal cell divisions during lateral root initiation. Proc. Natl. Acad. Sci. 116: 8597-8602.

Google Scholar: Author Only Title Only Author and Title

Ristova, D., Giovannetti, M., Metesch, K., and Busch, W. (2018). Natural genetic variation shapes root system responses to phytohormones in Arabidopsis. Plant J. 96: 468-481.

Google Scholar: Author Only Title Only Author and Title

Rowe, M.H., Dong, J., Weimer, AK., and Bergmann, D.C. (2019). APlant-Specific Polarity Module Establishes Cell Fate Asymmetry in the Arabidopsis Stomatal Lineage. bioRxiv: 614636.

Google Scholar: Author Only Title Only Author and Title

Ryu, K.H., Huang, L., Kang, H.M., and Schiefelbein, J. (2019). Single-Cell RNASequencing Resolves Molecular Relationships Among Individual Plant Cells. Plant Physiol. 179: 1444-1456.

Google Scholar: Author Only Title Only Author and Title

Santuari, L. et al. (2016). The PLETHORA Gene Regulatory Network Guides Growth and Cell Differentiation in Arabidopsis Roots. Plant Cell 28: 2937-2951.

Google Scholar: Author Only Title Only Author and Title 

available under aCC-BY-NC-ND 4.0 International license.

Schlereth, A, Möller, B., Liu, W., Kientz, M., Flipse, J., Rademacher, E.H., Schmid, M., Jürgens, G., and Weijers, D. (2010).

MONOPTEROS controls embryonic root initiation by regulating a mobile transcription factor. Nature 464: 913-916.

Google Scholar: Author Only Title Only Author and Title

Schmidt, T., Pasternak, T., Liu, K., Blein, T., Aubry-Hivet, D., Dovzhenko, A, Duerr, J., Teale, W., Ditengou, F.A, Burkhardt, H.,

Ronneberger, O., and Palme, K. (2014). The iRoCS Toolbox--3D analysis of the plant root apical meristem at cellular resolution. Plant J.

Cell Mol. Biol. 77: 806-814.

Google Scholar: Author Only Title Only Author and Title

Shahan, R., Hsu, C.-W., Nolan, T.M., Cole, B.J., Taylor, I.W., Yot, AH.C., Benfey, P.N., and Ohler, U. (2020). Asingle cell Arabidopsis root atlas reveals developmental trajectories in wild type and cell identity mutants. bioRxiv: 2020.06.29.178863.

Google Scholar: Author Only Title Only Author and Title

Shulse, C.N., Cole, B.J., Ciobanu, D., Lin, J., Yoshinaga, Y., Gouran, M., Turco, G.M., Zhu, Y., O'Malley, R.C., Brady, S.M., and Dickel, D.E. (2019). High-Throughput Single-Cell Transcriptome Profiling of Plant Cell Types. Cell Rep. 27: 2241-2247.e4.

Google Scholar: Author Only Title Only Author and Title

Siligato, R. et al. (2016). Multisite gateway-compatible cell type-specific gene-inducible system for plants. Plant Physiol. 170: 627-641. Google Scholar: Author Only Title Only Author and Title

Singh, S., Yadav, S., Singh, A, Mahima, M., Singh, A, Gautam, V., and Sarkar, AK. (2020). Auxin signaling modulates LATERAL ROOT PRIMORDIUM1 (LRP1) expression during lateral root development in Arabidopsis. Plant J. 101: 87-100.

Google Scholar: Author Only Title Only Author and Title

Smet, W. et al. (2019). DOF2.1 Controls Cytokinin-Dependent Vascular Cell Proliferation Downstream of TMO5/LHW. Curr. Biol. 29: 520529.e6.

Google Scholar: Author Only Title Only Author and Title

Smith, D.L. and Fedoroff, N.V. (1995). LRP1, a gene expressed in lateral and adventitious root primordia of arabidopsis. Plant Cell 7: 735-745.

Google Scholar: Author Only Title Only Author and Title

Snouffer, A, Kraus, C., and van der Knaap, E. (2020). The shape of things to come: ovate family proteins regulate plant organ shape. Curr. Opin. Plant Biol. 53: 98-105.

Google Scholar: Author Only Title Only Author and Title

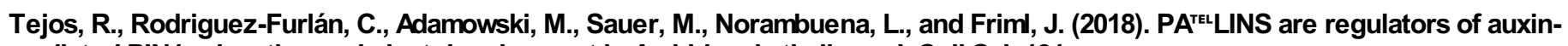
mediated PIN1 relocation and plant development in Arabidopsis thaliana. J. Cell Sci. 131.

Google Scholar: Author Only Title Only Author and Title

To, J.P.C., Haberer, G., Ferreira, F.J., Deruère, J., Mason, M.G., Schaller, G.E., Alonso, J.M., Ecker, J.R., and Kieber, J.J. (2004). Type-A Arabidopsis response regulators are partially redundant negative regulators of cytokinin signaling. Plant Cell 16: 658-671.

Google Scholar: Author Only Title Only Author and Title

Torres-Martínez, H.H., Hernández-Herrera, P., Corkidi, G., and Dubrovsky, J.G. (2020). From one cell to many: Morphogenetic field of lateral root founder cells in Arabidopsis thaliana is built by gradual recruitment. Proc. Natl. Acad. Sci. 117: 20943-20949.

Google Scholar: Author Only Title Only Author and Title

Toyokura, K. et al. (2019). Lateral Inhibition by a Peptide Hormone-Receptor Cascade during Arabidopsis Lateral Root Founder Cell Formation. Dev. Cell 48: 64-75.e5.

Google Scholar: Author Only Title Only Author and Title

Traag, V.A, Waltman, L., and van Eck, N.J. (2019). From Louvain to Leiden: guaranteeing well-connected communities. Sci. Rep. 9: 5233. Google Scholar: Author Only Title Only Author and Title

Trapnell, C., Cacchiarelli, D., Grimsby, J., Pokharel, P., Li, S., Morse, M., Lennon, N.J., Livak, K.J., Mikkelsen, T.S., and Rinn, J.L. (2014). The dynamics and regulators of cell fate decisions are revealed by pseudotemporal ordering of single cells. Nat. Biotechnol. 32: 381386.

Google Scholar: Author Only Title Only Author and Title

Trinh, D.-C. et al. (2019). PUCHI regulates very long chain fatty acid biosynthesis during lateral root and callus formation. Proc. Natl.

Acad. Sci. U. S. A 116: 14325-14330.

Google Scholar: Author Only Title Only Author and Title

Uga, Y. et al. (2013). Control of root system architecture by DEEPER ROOTING 1 increases rice yield under drought conditions. Nat. Genet. 45: 1097-1102.

Google Scholar: Author Only Title Only Author and Title

Vanneste, S. et al. (2005). Cell Cycle Progression in the Pericycle Is Not Sufficient for SOLITARY ROOT/IAA14-Mediated Lateral Root Initiation in Arabidopsis thaliana. Plant Cell 17: 3035-3050.

Google Scholar: Author Only Title Only Author and Title

Vermeer, J.E.M., Wangenheim, D. von, Barberon, M., Lee, Y., Stelzer, E.H.K., Maizel, A, and Geldner, N. (2014). A Spatial

Accommodation by Neighboring Cells Is Required for Organ Initiation in Arabidopsis. Science 343: 178-183. 
Voß, U. et al. (2015). The circadian clock rephases during lateral root organ initiation in Arabidopsis thaliana. Nat. Commun. 6: 7641. Google Scholar: Author Only Title Only Author and Title

Waite, J.M., Collum, T.D., and Dardick, C. (2020). AtDRO1 is nuclear localized in root tips under native conditions and impacts auxin localization. Plant Mol. Biol. 103: 197-210.

Google Scholar: Author Only Title Only Author and Title

Wang, S., Chang, Y., and Ellis, B. (2016). Overview of OVATE FAMILY PROTEINS, ANovel Class of Plant-Specific Growth Regulators. Front. Plant Sci. 7.

Google Scholar: Author Only Title Only Author and Title

Wang, S., Chang, Y., Guo, J., Zeng, Q., Ellis, B.E., and Chen, J.-G. (2011). Arabidopsis ovate family proteins, a novel transcriptional repressor family, control multiple aspects of plant growth and development. PloS One 6: e23896.

Google Scholar: Author Only Title Only Author and Title

Wang, Z-P., Xing, H.-L., Dong, L., Zhang, H.-Y., Han, C.-Y., Wang, X.-C., and Chen, Q.-J. (2015). Egg cell-specific promoter-controlled CRISPR/Cas9 efficiently generates homozygous mutants for multiple target genes in Arabidopsis in a single generation. Genome Biol. 16: 144 .

Google Scholar: Author Only Title Only Author and Title

Weber, E., Engler, C., Gruetzner, R., Werner, S., and Marillonnet, S. (2011). A Modular Cloning System for Standardized Assembly of Multigene Constructs. PLOS ONE 6: e16765.

Google Scholar: Author Only Title Only Author and Title

Wilmoth, J.C., Wang, S., Tiwari, S.B., Joshi, AD., Hagen, G., Guilfoyle, T.J., Alonso, J.M., Ecker, J.R., and Reed, J.W. (2005). NPH4/ARF7 and ARF19 promote leaf expansion and auxin-induced lateral root formation. Plant J. Cell Mol. Biol. 43: 118-130.

Google Scholar: Author Only Title Only Author and Title

Wolock, S.L., Lopez, R., and Klein, AM. (2019). Scrublet: Computational Identification of Cell Doublets in Single-Cell Transcriptomic Data. Cell Syst. 8: 281-291.e9.

Google Scholar: Author Only Title Only Author and Title

Xun, Q., Wu, Y., Li, H., Chang, J., Ou, Y., He, K., Gou, X., Tax, F.E., and Li, J. (2020). Two receptor-like protein kinases, MUSTACHES and MUSTACHES-LIKE, regulate lateral root development in Arabidopsis thaliana. New Phytol. 227: 1157-1173.

Google Scholar: Author Only Title Only Author and Title

Yi, D. et al. (2014). The Arabidopsis SIAMESE-RELATED Cyclin-Dependent Kinase Inhibitors SMR5 and SMR7 Regulate the DNA Damage Checkpoint in Response to Reactive Oxygen Species[W]. Plant Cell 26: 296-309.

Google Scholar: Author Only Title Only Author and Title

Yoo, S.-D., Cho, Y.-H., and Sheen, J. (2007). Arabidopsis mesophyll protoplasts: a versatile cell system for transient gene expression analysis. Nat. Protoc. 2: 1565-1572.

Google Scholar: Author Only Title Only Author and Title

Zeng, Q., Sritubtim, S., and Ellis, B.E. (2011). AtMKK6 and AtMPK13 are required for lateral root formation in Arabidopsis. Plant Signal. Behav. 6: 1436-1439.

Google Scholar: Author Only Title Only Author and Title

Zhu, Y., Dong, A, Meyer, D., Pichon, O., Renou, J.-P., Cao, K., and Shen, W.-H. (2006). Arabidopsis NRP1 and NRP2 encode histone chaperones and are required for maintaining postembryonic root growth. Plant Cell 18: 2879-2892.

Google Scholar: Author Only Title Only Author and Title 